(C) 2018. This manuscript version is made available under the CC-BY-NC-ND 4.0 license http:// creativecommons.org/licenses/by-nc-nd/4.0/

\title{
The Application of Multi-mission Satellite Data Assimilation for Studying Water Storage Changes over South America
}

\author{
M. Khaki ${ }^{\mathrm{a}, \mathrm{b}, 1}$, J. Awange ${ }^{\mathrm{a}}$ \\ ${ }^{a}$ School of Earth and Planetary Sciences, Spatial Sciences, Curtin University, Perth, Australia. \\ ${ }^{b}$ School of Engineering, University of Newcastle, Callaghan, New South Wales, Australia.
}

\begin{abstract}
Constant monitoring of total water storage (TWS; surface, groundwater, and soil moisture) is essential for water management and policy decisions, especially due to the impacts of climate change and anthropogenic factors. Moreover, for most countries in Africa, Asia, and South America that depend on soil moisture and groundwater for agricultural productivity, monitoring of climate change and anthropogenic impacts on TWS becomes crucial. Hydrological models are widely being used to monitor water storage changes in various regions around the world. Such models, however, comes with uncertainties mainly due to data limitations that warrant enhancement from remotely sensed satellite products. In this study over South America, remotely sensed TWS from the Gravity Recovery And Climate Experiment (GRACE) satellite mission is used to constrain the World-Wide Water Resources Assessment (W3RA) model estimates in order to improve their reliabilities. To this end, GRACE-derived TWS and soil moisture observations from the Advanced Microwave Scanning Radiometer - Earth Observing System (AMSR-E) and Soil Moisture and Ocean Salinity (SMOS) are assimilated into W3RA using the Ensemble Square-Root Filter (EnSRF) in order to separately analyze groundwater and soil moisture changes for the period 2002-2013. Following the assimilation analysis, Tropical Rainfall Measuring Mission (TRMM)'s rainfall data over 15 major basins of South America and El Niño/Southern Oscillation (ENSO) data are employed to demonstrate the advantages gained by the model from the assimilation of GRACE TWS and satellite soil moisture products in studying climatically induced TWS changes. From the results, it can be seen that assimilating these observations improves the performance of W3RA hydrological model. Significant improvements are also achieved as seen from increased correlations between TWS products and both precipitation and ENSO over a majority of basins. The improved knowledge of sub-surface water storages, especially groundwater and soil moisture variations, can be largely helpful for agricultural productivity over South America.
\end{abstract}

Email address: Mehdi.Khaki@postgrad.curtin.edu.au (M. Khaki) 
Keywords: South America, Satellite remote sensing, Data assimilation, Hydrological modelling, GRACE, Satellite soil moisture

\section{Introduction}

South America, with unique ecosystems and a high biodiversity, has extreme geographic variations and diverse patterns of weather and climate that include tropical, subtropical and extratropical features (Garreaud et al., 2008). The region is largely under the influence of largescale ocean-atmosphere phenomena including mainly El Niño Southern Oscillation (ENSO) and the North Atlantic Oscillation (NAO), which affects climate and its phases associated with droughts, floods, and extreme weather events within different parts of the continent (Magrin et al., 2007; Tedeschi and Collins, 2016). Climate variability throughout South America can be categorized based on the distance from the equator and the altitude of the area. The Andes mountain ranges, running along South America's western side, plays an important role in tropical as well as subtropical latitudes by keeping dry conditions on the west and moist conditions on the east (Garreaud et al., 2008). These climate variabilities, e.g., due to the different climatic zones across the continent and/or large-scale ocean-atmosphere phenomena, have significant impacts on the continent's water storages (surface water, groundwater, soil moisture, and vegetation water). There are other important factors that largely threaten water resources such as excessive water use, especially for agricultural purposes (Grau and Aide, 2008; Magrin et al., 2014). Therefore, the study of South America's water storage changes in light of the climate change and anthropogenic impacts is necessary for any future water use planning.

To study South America's water storage changes at high spatio-temporal resolutions, hydrological models have come in handy (e.g., Betts et al., 1996; Koster et al., 1999; Döll et al., 2003; van Dijk, 2010; De Paiva et al., 2013; Getirana et al., 2014), particularly over the regions with a few ground-based observations such as Venezuela, Ecuador, Chile, and Peru. The applications of these models are especially important for agriculture and sustainable water managements (e.g., Bharati et al., 2008; Yu et al., 2015; Kourgialas and Karatzas, 2015). However, in general, data limitations and other factors, e.g., imperfect modeling and uncertainties of model parameters can weaken performances of the models for simulation of hydrological processes (van Dijk et al., 2011; Vrugt et al., 2013). In this regards, data assimilation provides a unique opportunity to improve model reliabilities (Bertino et al., 2003). This approach integrates additional observations that have not been considered in those models into their dynamics to constrain its 
state estimates (Bertino et al., 2003; Hoteit et al., 2012).

Data assimilation has been used in different applications, e.g., atmospheric fields (Elbern and Schmidt, 2001; Schunk et al., 2004; Altaf et al., 2014), oceanic (Bennett, 2002; Lahoz, 2007) and magnetospheric (Garner et al., 1999) studies. The method has also been applied in hydrological contexts to increase models' performances for estimating various water compartments (e.g., Reichle et al., 2002; Alsdorf et al., 2007; Goncalves et al., 2009; Renzullo et al., 2014; Dillon et al., 2016; Khaki et al., 2018a,b). The use of models to study hydrological variables over South America are reported, e.g., in the works of Yates et al. (1997), Chou et al. (2002), Grimson et al. (2013), and Erfanian et al. (2017), who investigate the application of the models on hydrological resources, droughts, and water storage changes. In the works above, the limitations have been that the models have not incorporated remotely sensed hydrological products such as the Gravity Recovery And Climate Experiment (GRACE) with a large capability of estimating terrestrial water storage (TWS) changes.

The main objective of the present study is, therefore, to use multimission satellite data products to improve hydrological model estimates of sub-surface water storages over South America. For this purpose, GRACE-derived TWS and soil moisture observations from the Advanced Microwave Scanning Radiometer - Earth Observing System (AMSR-E) and Soil Moisture and Ocean Salinity (SMOS) are assimilated into the World-Wide Water Resources Assessment (W3RA) hydrological model (van Dijk, 2010). The model has been applied at different continental and global studies including South America (e.g., van Dijk et al., 2013, 2014; Beck et al., 2016; Schellekens et al., 2017). In terms of observations, several studies indicate that using GRACE TWS (e.g., Zaitchik et al., 2008; Houborg et al., 2012; Li et al., 2012; Eicker et al., 2014; Li et al., 2015; Reager et al., 2015; Li and Rodell, 2015; Kumar et al., 2016; Girotto et al., 2016; Khaki et al., 2017a,b; Girotto et al., 2017; Khaki et al., 2018c) and satellite soil moisture (e.g., Tian et al., 2008; Renzullo et al., 2014; Dumedah et al., 2015; Tian et al., 2017; Kolassa et al., 2017) for data assimilation can successfully constrain the hydrological models simulations. The present study aims at investigating the effectiveness of multi-satellite data assimilation for studying sub-surface water storage changes using a nonregional hydrological model. It should be pointed out that although similar studies by the authors have been undertaken for other regions and using different products (e.g., Khaki et al., 2017c, 2018d), the main distinction and innovativeness between the current work over South America and those undertaken by the authors above, is that for the first time, both GRACE 
TWS and soil moisture products are employed in assimilation over the area. Furthermore, the contribution of climate variability on South America's water storage derived from assimilation using satellite precipitation products is also investigated.

Assimilation of GRACE TWS data allows users to consistently separate TWS (since both model and observation errors are considered) into different water compartments that include groundwater and soil moisture. This is due to the fact that the W3RA model relies on the physical processes implemented in the model equations. Besides, GRACE-derived TWS observations are spatially downscaled using this approach, and therefore, higher spatial resolution estimations of water storages will be available within the study region (see, e.g., Schumacher et al., 2016). Moreover, the application of soil moisture observations in the assimilation can improve the performance of the process by separately updating model soil moisture estimates (e.g., Tian et al., 2017). For the purpose of data assimilation, here, we use the ensemble-based sequential technique of the Ensemble Square-Root Filter (EnSRF) filtering scheme (Whitaker and Hamill, 2002) to integrate GRACE TWS into W3RA. EnSRF, as shown in Khaki et al. (2017a), is preferred over the traditional ensemble Kalman filter (e.g., Evensen, 2003, 2007; Eicker et al., 2014) due to its higher computational speed, simplicity, and independence of perturbed observations.

Following the assimilation step, in-situ measurements are used to assess the performance of the approach. Furthermore, the study investigates the use of the model to study climate induced water storage changes by comparing correlations between assimilated and non-assimilated results with climate variability indicators of the Tropical Rainfall Measuring Mission (TRMM) rainfall and ENSO ocean-atmospheric couple indicator. For a better discussion, the study area is divided into 15 major basins selected (Figure 1) based on their importance and large hydro-climatic effects, which also allow us to spatially have a better analysis. We also apply principal component analysis (PCA, Lorenz, 1956) on the TRMM rainfall data, groundwater, soil moisture results from model over each basin to better understand the spatial and temporal variations of water storages and their interactions with precipitation. Frappart et al. (2013) found that PCA modes can better represent spatiotemporal variations in time series compared to the full signals by separating dominant water mass change signals, especially over South America (see also Abelen et al., 2015).

In the remainder of this study, first, datasets and method are presented in Section 2. We then discuss the data assimilation filtering scheme in Subsection 2.5 and provide a detailed 


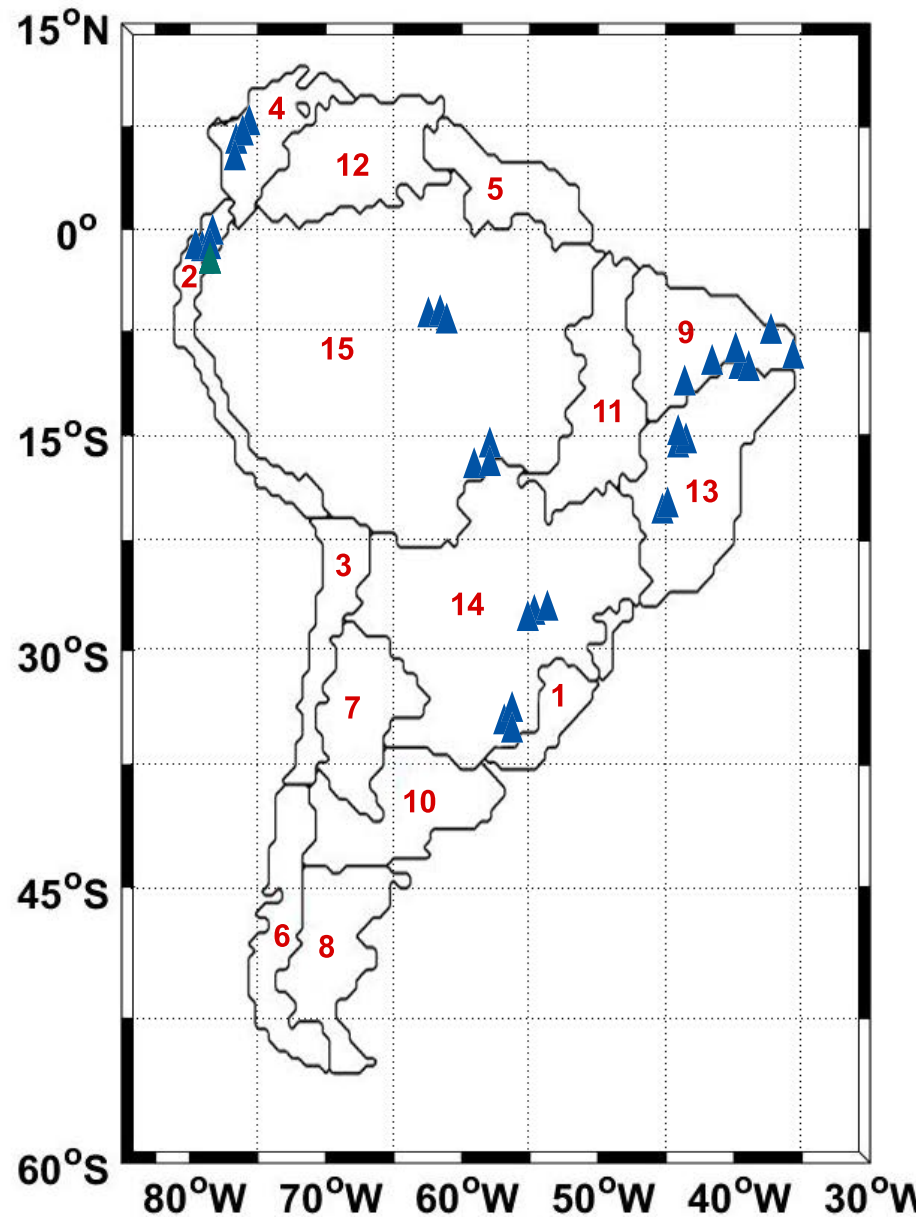

\begin{tabular}{|c|l|}
\hline 1 & South-east Atlantic \\
\hline 2 & Pacific Coast, Peru \\
\hline 3 & Pacific Coast, North Chile \\
\hline 4 & Magdalena \\
\hline 5 & Atlantic North Coast \\
\hline 6 & Pacific Coast, South Chile \\
\hline 7 & Colorado Basin \\
\hline 8 & Atlantic South Coast \\
\hline 9 & North-east Atlantic \\
\hline 10 & Negro Basin \\
\hline 11 & Tocantins \\
\hline 12 & Orinoco \\
\hline 13 & Sao Francisco \\
\hline 14 & La Plata \\
\hline 15 & Amazon Basin \\
\hline
\end{tabular}

Groundwater in-situ measurements

Figure 1: Overview of the study area. The black polygons indicate the 15 river basins considered. These basins are selected according to HydroSHEDS (http://www.hydrosheds.org/) classification with small modifications to combine smaller basins and also for a better representation. The basins are sorted according to their areas. Data from in-situ groundwater stations (blue triangles) are used to provide independent validation of the assimilation results.

\section{Materials and methods}

\subsection{W3RA hydrological model}

Vertical water compartments (e.g., soil moisture, groundwater, and surface water) of the globally distributed $1^{\circ} \times 1^{\circ}$ World-Wide Water Resources Assessment system (W3RA; http://www.wenfo.org/wald/data-software/) model are used to simulate water storage over 
South America. The model was developed in 2008 by the Commonwealth Scientific and Industrial Research Organisation (CSIRO; Australia) to simulate water storages (van Dijk, 2010). In terms of forcing data, minimum and maximum temperature, downwelling short-wave radiation, and precipitation products provided by Princeton University (http://hydrology.princeton.edu) are used. Daily W3RA estimates of top, shallow, and deep root soil layers, groundwater storage, and surface water storage in a one-dimensional system (vertical variability) are used for data assimilation (see details in Subsection 2.6).

\subsection{Remotely sensed observations (GRACE, soil moisture and TRMM products)}

\subsubsection{GRACE TWS}

Monthly TWS observations at a $3^{\circ} \times 3^{\circ}$ spatial resolution (suggested by Khaki et al., 2017b, for data assimilation objectives) derived from the GRACE level 2 (L2) monthly Stokes's coefficients (following Wahr et al., 1998) up to degree and order 90 are used for the assimilation. L2 products along with their full error information are obtained from the ITSG-Grace2014 gravity field model (Mayer-Gürr et al., 2014) for the period between 2002 and 2013. Before converting L2 data into TWS, low degree coefficients of 1 and 2 (C20) are respectively replaced by those estimated by Swenson et al. (2008) and Satellite Laser Ranging solutions, respectively, to account for the change in the Earth's center of mass and large uncertainties (e.g., Cheng and Tapley, 2004; Chen et al., 2007). The DDK2 smoothing filter by Kusche et al. (2009) is applied to tackle colored/correlated noises in spherical harmonics. In order to reduce leakage effects, for every one of the 15 basins considered, an isotropic kernel using a Lagrange multiplier filter proposed by Swenson and Wahr (2002) is applied. This approach reduces short wavelength effects using Lagrange multiplier to minimize the leakage for a given value of satellite error. Here, the satellite error is selected based on the acquired GRACE full error covariance matrix. Khaki et al. (2018e) showed that this filtering technique can effectively reduce leakage errors, e.g., over Amazon basin. Finally, the mean TWS for the study period is taken from W3RA and added to the GRACE TWS change time series to obtain absolute values and make them comparable with model outputs (Zaitchik et al., 2008).

\subsubsection{Satellite soil moisture}

In addition, soil moisture observations from the Advanced Microwave Scanning Radiometer for EOS (AMSR-E), between 2002 and 2011, and ESA's Soil Moisture Ocean Salinity (SMOS) Earth Explorer mission, between 2011 and 2013, are used in the data assimilation to 
update model soil moisture variabilities. The AMSR-E measurements are correlated to the surface 0-2 cm soil moisture content (Njoku et al., 2003), while SMOS maps land soil moisture for the 0-5 cm depth. Level 3 CATDS (Centre Aval de Traitement des Donnees SMOS) products (Jacquette et al., 2010) are acquired. SMOS and AMSR-E are selected from ascending and descending passes, respectively, subject to their higher agreement to in-situ measurements (see, e.g., De Jeu and Owe, 2003; Draper et al., 2009; Jackson and Bindlish, 2012; Su et al., 2013).

Both data products with a daily temporal resolution are spatially rescaled from $0.25^{\circ} \times 0.25^{\circ}$ to $1^{\circ} \times 1^{\circ}$ resolution using the nearest neighbor interpolation to match W3RA. Note that these soil moisture observations are used in different periods during the assimilation process, i.e., AMSRE soil moisture is assimilated for the period 2002-2011 and SMOS soil moisture is assimilated for the period 2011-2013.

\subsubsection{Precipitation}

Furthermore, monthly precipitation data of the Tropical Rainfall Measuring Mission Project (TRMM-3B43 products; version 7, TRMM, 2011; Huffman et al., 2012) are used to assess climate induced water storage changes. Due to the fact that ground validation over land is applied for TRMM-3B43 products, uncertainty in measured precipitation are smaller compared to those of the oceans. Several studies have implemented and validated these products over South America and proved their capabilities (see, e.g., Condom et al., 2011; Ceccherini et al., 2015; Cabrera et al., 2016). The rainfall data are provided on a $0.25^{\circ} \times 0.25^{\circ}$ gridded spatial resolution and to make them comparable to those of the model (cf. Section 2.1), they are converted to $1^{\circ} \times 1^{\circ}$ using the nearest neighbor interpolation for the period of 2002 to 2013 .

\subsection{Surface storage data}

Although the focus of the present study is on sub-surface water storage compartments, in order to efficiently assimilate GRACE TWS data into W3RA, however, a special focus should be invested on surface water storage variations due to their large contribution in water storage changes over South America (Getirana et al., 2017). In particular, this is important because many surface water sources (in different forms, e.g., lakes and rivers, except for a few major ones) are not modeled in W3RA. To address this problem, the recently developed surface water storage data provided by Getirana et al. (2017) is used. The data is based on a coupled system compromising Noah land surface model (LSM) with multi-parameterization options (Noah-MP; Niu et al., 2011) and the Hydrological Modeling and Analysis Platform (HyMAP) river routing 
scheme (Getirana et al., 2012). Multiple meteorological forcings and precipitation datasets are used to generate an ensemble of 12 runs, and to establish reference product with associated uncertainties (see details in Getirana et al., 2017). The $1^{\circ} \times 1^{\circ}$ monthly gridded surface water data for the period of 2012 to 2013 are subtracted from GRACE TWS before data assimilation.

\subsection{In-situ groundwater measurements}

In order to evaluate the obtained data assimilation results, independent in-situ groundwater measurements over 34 stations obtained from Global Groundwater Network (GGMN; https://ggmn.un-igrac.org/) and propagated within the study area (see Figure 1) are compared with estimated groundwater storage changes obtained from data assimilation. Groundwater level measurements should be converted into groundwater (GW) storage, which requires specific yield values. In the absence of such information, following Tangdamrongsub et al. (2015), TWS variation from GRACE and Global Land Data Assimilation System (GLDAS, Rodell et al., 2004) soil moisture are used to calculate the specific yield and scale the observed head. The scaled in-situ groundwater level fluctuations are then used to assess the results. Afterwards, the assimilation results are spatially interpolated to the location of the in-situ measurements using the nearest neighbor (the closest four grid values). The Root-Mean-Squared Error (RMSE) and correlations between the in-situ and estimated groundwater storage measurements are then computed.

\subsection{Data assimilation filtering method}

The filtering technique of Ensemble Square-Root Filter (EnSRF) proposed by Whitaker and Hamill (2002) is used to assimilate GRACE TWS and soil moisture data into the W3RA model. The method is based on a traditional Ensemble Kalman Filter (EnKF) that poses a new sampling scheme. The filtering process starts with the forecast step, which includes integrating $N$ (ensemble number) samples of model state $X$ that contains top soil, shallow soil, and deep soil water, snow, vegetation, and groundwater by a dynamical model. The forecast state, thus, can be shown as,

$$
X^{f}=\left[X_{1}^{f} \ldots X_{N}^{f}\right], X_{i}^{f} i=1 \ldots N,
$$


where 'f' stands for forecast ('a' in following represents analysis). The corresponding model state forecast error covariance of $P^{f}$ and the mean state forecast $\bar{X}^{f}$ are defined by:

$$
\begin{gathered}
P^{f}=\frac{1}{N-1} \sum_{i=1}^{N}\left(X_{i}^{f}-\bar{X}^{f}\right)\left(X_{i}^{f}-\bar{X}^{f}\right)^{T}, \\
\bar{X}^{f}=\frac{1}{N} \sum_{i=1}^{N}\left(X_{i}\right) .
\end{gathered}
$$

The update stage in EnSRF contains two steps. First, it updates the ensemble-mean following,

$$
\begin{gathered}
\bar{X}^{a}=\bar{X}^{f}+K\left(y-H \bar{X}^{f}\right), \quad i=1 \ldots N, \\
K=P^{f}(H)^{T}\left(H P^{f}(H)^{T}+R\right)^{-1},
\end{gathered}
$$

where $K$ is the Kalman gain, $y$ is the observation vector and transition matrix is indicated by $H$. $R$ represents the observation covariance matrix. Data assimilation methods are largely sensitive to the observations uncertainties. Therefore, it is important to assign accurate error values to each observation used in data assimilation. Here, for GRACE observations, TWS error covariance matrix is constructed from Full error information about the GRACE Stokes' coefficients. There is no covariance error information available for satellite soil moisture observations, thus, we assume their error covariances to be uncorrelated and consider various uncertainties to monitor their impacts on data assimilation by comparing the results with independent measurements. This allows us to obtain optimum error values for soil moisture part of observation error covariance. Accordingly, $\mathbf{R}$ is assumed to be diagonal with an error standard deviation of $0.04\left(\mathrm{~m}^{3} \mathrm{~m}^{-3}\right)$ for SMOS (suggested by Leroux et al., 2016) and $0.05\left(\mathrm{~m}^{3} \mathrm{~m}^{-3}\right)$ for AMSR-E (suggested by De Jeu et al., 2008). In addition, for the observation error covariance in simultaneous data assimilation case, GRACE data and both SMOS and AMSR-E observations are assumed to be uncorrelated. It is worth mentioning that more study is still required to efficiently estimate the spatially varying observations uncertainties, which also account for error correlations. This can lead to different results and potentially improved data assimilation. $\bar{X}^{a}$ in Equation 4 is the analysis ensemble-mean. In the next step, i.e., the analysis step, the 
filter updates the forecast ensemble of anomalies,

$$
\begin{gathered}
A^{f}=\left[A_{1}{ }^{f} \ldots A_{N}{ }^{f}\right], \\
A_{i}{ }^{f}=X_{i}{ }^{f}-\bar{X}^{f},
\end{gathered}
$$

into the analysis ensemble deviation $A^{a}$ in Equation 8. EnSRF exploits the serial formulation of the Kalman filter analysis step in which the observations are assimilated each at a time to compute the analysis perturbations that exactly match the Kalman filter covariance (Hoteit et al., 2008) using the modified gain $(\tilde{K}=\alpha K)$ with,

$$
\begin{gathered}
A^{a}=(I-\tilde{K} H) A_{i}{ }^{f}, \\
\alpha=\left(1+\sqrt{\frac{R}{H P^{f} H^{T}+R}}\right)^{-1},
\end{gathered}
$$

where $I$ is an identity matrix. This definition requires the observation errors to be uncorrelated, which can always be satisfied by scaling the observations with the square-root inverse of the observational error covariance matrix (Hoteit et al., 2015). This, however, is not the case here because there is no rank deficiency on observation error covariance. We assume that soil moisture observations are uncorrelated. Furthermore, the correlation between GRACE TWS on the one hand and soil moisture observations, on the other hand, is also assumed to be zero. The rank deficiency issue raised from GRACE TWS block in the covariance matrix is mitigated by applying GRACE TWS observations in a $3^{\circ} \times 3^{\circ}$ spatial resolution along with the implementation of Local Analysis (LA) (Evensen, 2003) scheme, which restricts the information used for the covariance matrix computation to a spatially limited area and uses only measurements located within a certain distance from a grid point (cf. Section 2.6, see also Khaki et al., 2017b). More details regarding the EnSRF algorithm and its performance in GRACE TWS data assimilation against other filters are described, e.g., in Whitaker and Hamill (2002) and Khaki et al. (2017a).

\subsection{Experimental setup}

As already mentioned, the state vector includes different water storages, i.e., soil moisture, vegetation, snow, and groundwater, simulated by W3RA. Previous studies have investigated the surface water variations over South America (e.g., De Paiva et al., 2013; Getirana et al., 2017), thus, we only focus on the estimation of sub-surface compartments; groundwater 
and soil moisture. The modified GRACE TWS data (cf. 2.3) is then used to update the above water compartments excluding surface storage. The observation operator aggregates different water storages at each grid point (1688 points in total) to update with GRACE TWS and scales top-layer soil storage by the field capacity value to provide a relative wetness for updating with soil moisture products of AMSR-E and SMOS (Renzullo et al., 2014).

Considering the different temporal resolution of assimilation observations, e.g., monthly GRACE TWS and daily soil moisture measurements, both observation sets are temporally rescaled into a 5-day resolution for data assimilation. This is done to allow for a simultaneous data assimilation of GRACE TWS and satellite soil moisture measurements. Khaki et al. (2017b) showed that assimilating GRACE TWS in a 5-day temporal scale leads to a better improvement in state variables compared to daily and monthly scales. Therefore, in the analysis steps during the assimilation, the 5-day temporal average update increment (cf. Equation 4) is applied. In order to produce ensemble for EnSRF filtering, we use Monte Carlo sampling of multivariate normal distribution, with the errors representing the standard deviations to perturb three main forcing parameters; precipitation, temperature, and radiation (see details in Renzullo et al., 2014). Afterwards, by integrating perturbed meteorological forcing forward in time with the model from 2000 to 2002, 72 sets of state vectors (ensemble; as suggested by Oke et al., 2008) is created at the beginning of the study period.

While implementing data assimilation with a large number of ensemble members results in a heavy computational burden, using a small ensemble size can also be problematic, as it can lead to filter divergence or inaccurate estimation (Tippett et al., 2003). To address this issue, two filter tuning is applied including ensemble inflation and LA. Ensemble inflation helps ensemble members to adequately span the model sub-space by inflating prior ensemble deviation from the ensemble-mean and increases their variations (Anderson, 2001; Anderson et al., 2007). Various inflation factors $([1-1.8])$ are tested and their impacts ensemble spreads are monitored to determine the best value (i.e., 1.12). Furthermore, LA (Evensen, 2003; Ott et al., 2004) is applied to both account for a limited ensemble number and also GRACE limited spatial resolution. Applying GRACE TWS data on a high spatial resolution (e.g., $1^{\circ} \times 1^{\circ}$ ) causes correlation errors, which degrades the performance of data assimilation (Khaki et al., 2017a,b). Khaki et al. (2017b) showed that LA can successfully mitigate this problem by restricting the impact of the measurements in the update step to variables located within a certain distance only, e.,g, $5^{\circ}$, which is applied in the present study. 


\subsection{Climate variability impacts}

In order to investigate the model's enhancement for studying climate induced impacts, TRMM rainfall and ENSO data are employed. At each grid point, correlations between TWS with and without data assimilation for both rainfall (at the same point) and ENSO are calculated. Afterwards, improvements achieved by data assimilation with respect to no assimilation of TWS are explored. Furthermore, principal component analysis (PCA; Lorenz, 1956) is applied on the estimated groundwater and soil moisture storages (from assimilation), as well as on TRMM rainfall to better analyze the spatio-temporal changes of water storages and precipitation. This is done to examine the precipitation patterns within the area between 2002 and 2013 and to investigate their connections to water storage changes. Since precipitation is the major effective parameter on water storage recharge, the process helps to study the role of climate variability on water storage variations. A schematic illustration of the methodology steps is provided in Figure 2.

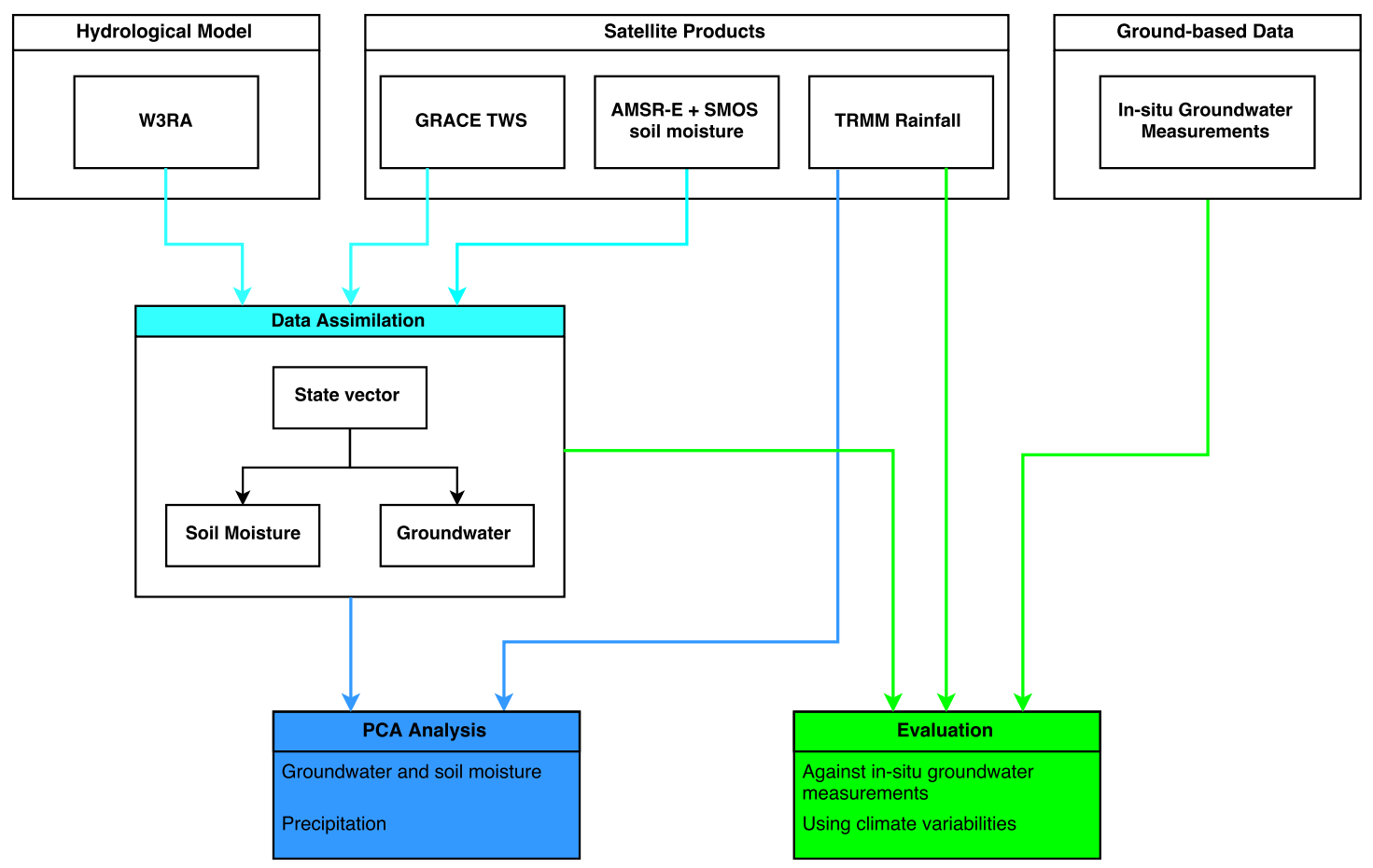

Figure 2: Schematic illustration of the methodology steps including data used, assimilation scheme, and evaluation processes. In data assimilation process, W3RA is used for forecasting and GRACE TWS and satellite soil moisture measurements are used to update forecasts from the model. Once the groundwater and soil moisture are estimated from the assimilation process, their relationship with rainfall data is investigated using PCA analysis. The in-situ groundwater measurements as well as rainfall data are further used to assess the data assimilation estimates. 


\section{Results and discussions}

\subsection{Data assimilation}

In what follows, data assimilations results and their comparison with in-situ measurements are first discussed. First, we investigate the impacts of assimilated observations, e.g., GRACE TWS and satellite soil moisture on water storage estimates (cf. Section 3.1.1). Note that the results presented in this section are not used for validation and only show how the assimilation results differ from the open-loop (no data assimilation) results. Evaluation against independent measurements will also be discussed (cf. Section 3.1.2).

\subsubsection{Observation impacts on state variables}

The spatially averaged time series of TWS variations estimated by EnSRF over South America is presented in Figure 3a, which shows that the application of data assimilation reduces misfits (Figure 3b) between the results and GRACE TWS compared to the open-loop. Furthermore, Figure 3c shows the average time series of soil moisture variations from the model top layer open-loop and assimilation, as well as satellite remote sensing. Similar to Figure 3b, Figure 3d indicate that the data assimilation successfully decreases the differences between soil moisture estimates and the observations. The average discrepancy between the estimated (assimilated) TWS and those by GRACE is approximately $46 \%$, and between soil moisture estimates and satellite (AMSR-E and SMOS) observations is 34\% less than those of between open-loop and observations, which demonstrate that data assimilation successfully incorporates observations into the system states. The effects of data assimilation can better be seen where large anomalies exist such as 2005 and 2011. The large anomaly in Figure 3a during 2011 could be related to the strong ENSO impact (see, e.g., Boening et al., 2012). It is clear that this strong anomaly captured by GRACE is successfully reflected into assimilation TWS contrary to that of open-loop. 
(a)

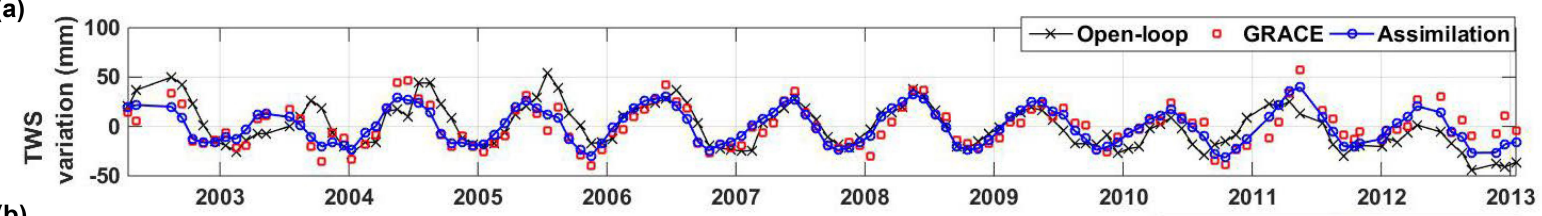

(b)

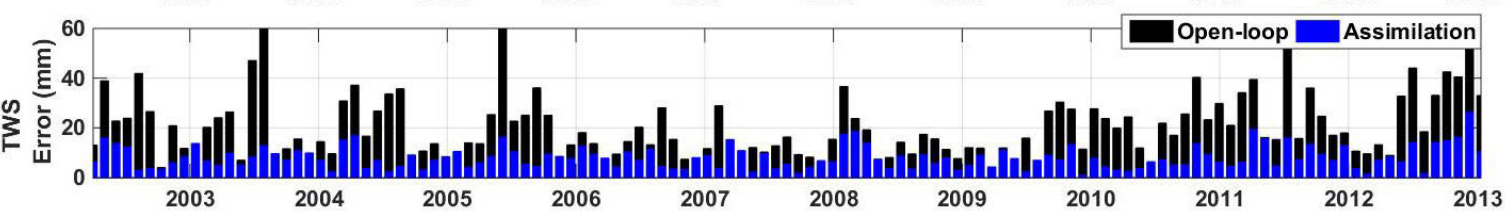

(c)
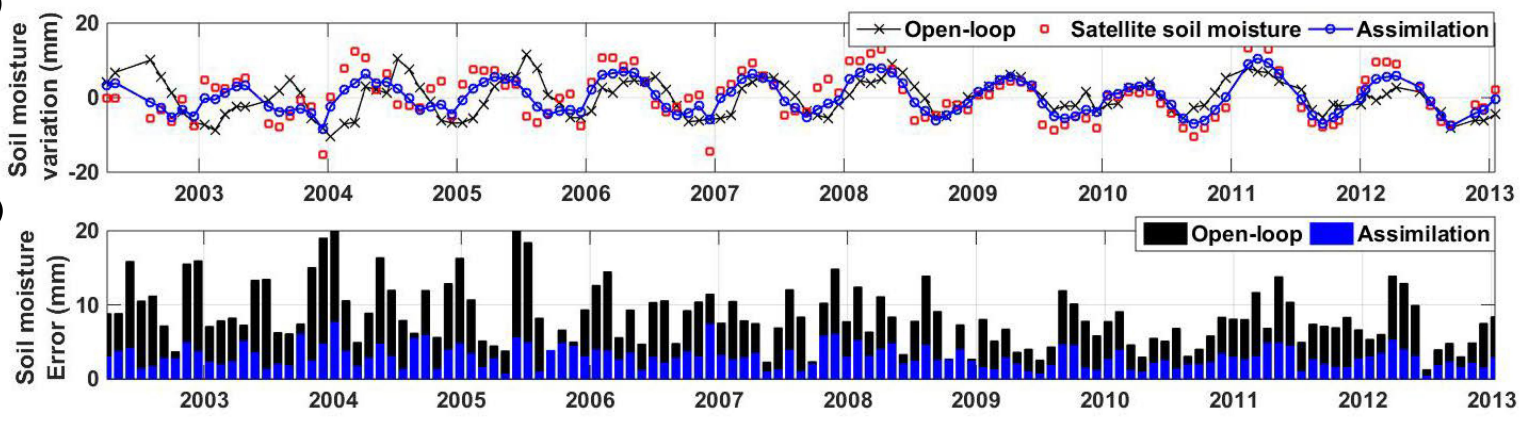

(e)

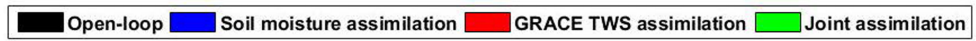

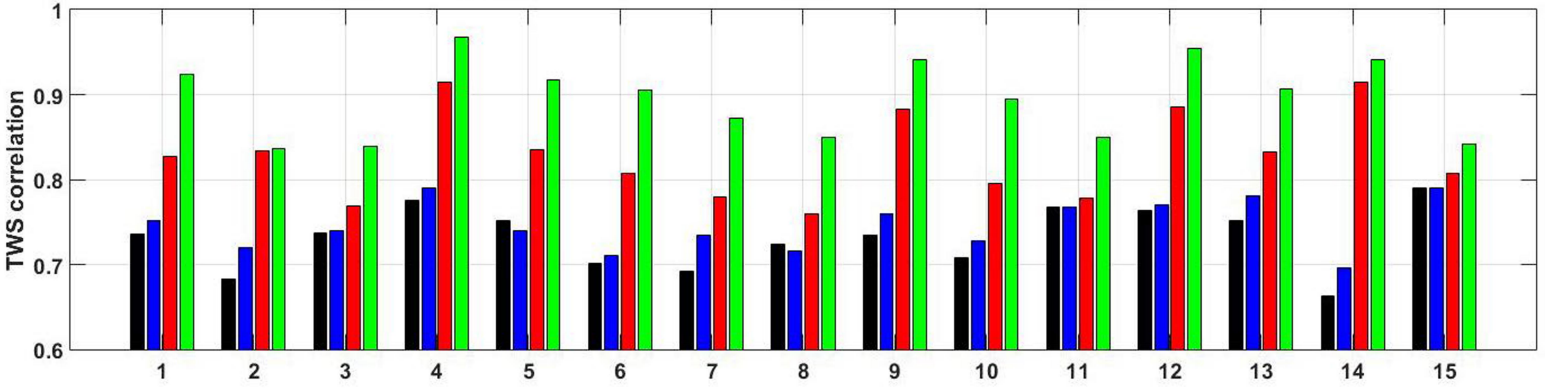

(f)

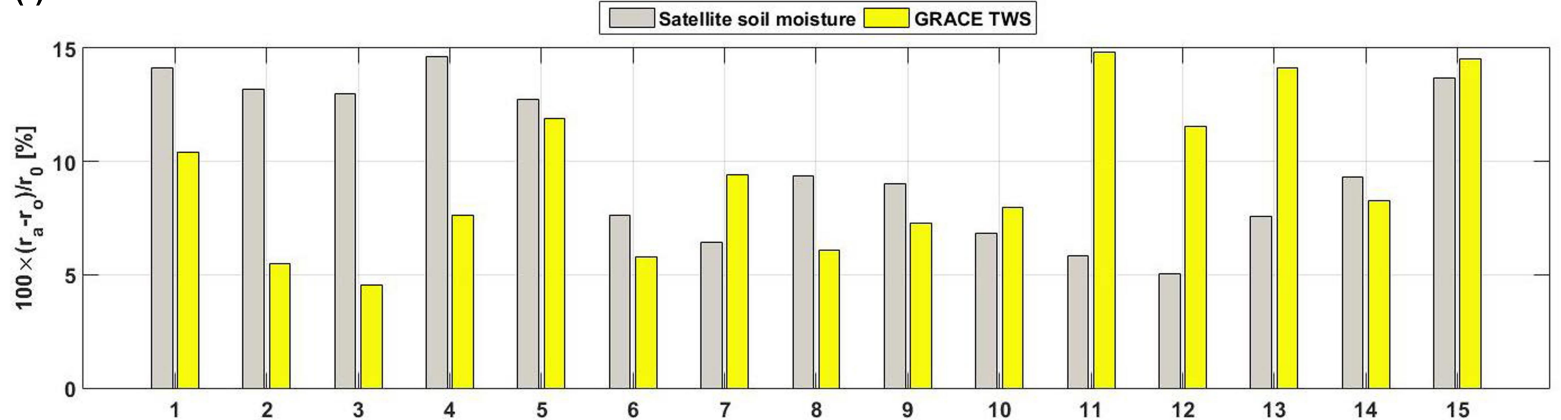

Figure 3: (a) Comparison between the TWS time series from the assimilation process (blue), GRACE TWS (red), with the open-loop referring to the model estimation without applying data assimilation (black). (b) Absolute error bars before (black) and after (blue) data assimilation process in comparison to the GRACE TWS observations. (c) and (d) are similar to (a) and (b), respectively, but for soil moisture observations. (e) Average correlations between GRACE-derived TWS and TWS simulated by W3RA before assimilation, GRACE TWS only assimilation, soil moisture only assimilation, and joint data assimilation for each basin (cf. Figure 1). (f) Correlation improvement between joint data assimilation results and GRACE TWS and soil moisture observation with respect to the open-loop results. 
For a better discussion, we also calculate the correlation between the soil moisture variations from satellites and estimations for each of the 15 basins (Figure 3e). This is done on a basin scale due to the fact that basin averaged time series can be more representative of water storage changes in the area. In all the cases, regardless of the method, data assimilation resulted in higher correlations with the observations compared to the open-loop (un-assimilated model products). Assimilation of only one satellite products, e.g., GRACE TWS or soil moisture, increases the correlation values in Figure 3e. As expected, GRACE TWS data assimilation has more effects on enhancing TWS correlations, however, it can be seen that even soil moisture only data assimilation in most of the cases causes higher TWS correlation than the open-loop results. It can also be seen that the correlation between joint data assimilation (GRACE TWS and satellite soil moisture) results in Figure 3e are largely in agreement with the observed variables compared to GRACE-only data assimilation. This indicates that assimilation of soil moisture products along with GRACE TWS leads to more improvements. One main reason for this is that while GRACE TWS data assimilation is generally an effective approach for updating models TWS (e.g., Zaitchik et al., 2008; Reager et al., 2015; Khaki et al., 2018a,b), it can also introduce artifact effects to different storage such as by assigning wrong increments to either groundwater or soil moisture (Li et al., 2015; Girotto et al., 2017; Khaki et al., 2018c). Assimilation of soil moisture products can account for this problem by independently constraining soil moisture estimates. Figure 3e shows that this joint assimilation leads to better estimations of soil moisture.

In addition, the average correlation improvement from jointly assimilating GRACE TWS and soil moisture in comparison to the open-loop is presented in Figure 3f. Note that only the results of joint data assimilation are presented in the figure due to its better performance (cf. Figure 3e). Figure $3 \mathrm{f}$ demonstrates that higher correlations are achieved after data assimilation. For GRACE TWS, higher correlations are achieved within larger basins such as Amazon (number 15) and Tocantins (number 11). This suggests that GRACE TWS data assimilation has larger impacts on these basins. It can be seen that the minimum improvement happens for the Pacific Coast, North Chile basin (number 3), where GRACE TWS data are expected to have larger errors in comparison to other basins like the Amazon basin with small leakage errors (Wiese, 2015). Nevertheless, in general, the assimilation process increases the correlation between outputs and GRACE TWS. 


\subsubsection{Evaluation results}

In order to examine the validity of the data assimilation, groundwater in-situ measurements from various stations are spatially averaged to the location of nearest model grid points and compared with their estimates. As mentioned (cf. Section 2.4), we calculate RMSE and correlation for three tests including the open-loop, GRACE-only TWS data assimilation, and joint GRACE-soil moisture assimilation. Table 1 presents the average RMSE, corresponding RMSE reduction, and Nash-Sutcliffe coefficient (NSE) of the results before and after assimilation. In order to statistically assess the significance of the results, the student t-test is applied after considering the autocorrelation in time series. The estimated t-values and the distribution at 0.05 significant level are used to calculate p-values. Data assimilation results indicate significantly smaller RMSE and higher NSE in cases of GRACE TWS and joint data assimilation. Soil moisture only data assimilation has small positive impacts on NSE improvement (e.g., 3\%) but with no significant RMSE improvement. An average improvement of $23.43 \%$ in RMSE and $14.08 \%$ in NSE (for all assimilation experiments) proves the capability of data assimilation to improve model simulations with respect to the reality. Nevertheless, the joint data assimilation indicates larger improvements in terms of RMSE reduction and NSE improvements than GRACE-only data assimilation. This shows that this method can better constrain different water storage compartments. It can be seen that soil moisture observations help in better controlling the distribution of increments between storages.

Table 1: Statistics of groundwater errors. For each case, the RMSE average and its range $( \pm \mathrm{XX})$ at the $95 \%$ confidence interval is presented. Improvements in data assimilation results are calculated with respect to the groundwater storages from the model without implementing data assimilation.

\begin{tabular}{lcccc}
\hline & & & \multicolumn{2}{c}{ Improvement (\%) } \\
\cline { 4 - 5 } Experiment scenario & NSE & RMSE (mm) & NSE & RMSE \\
\hline $\begin{array}{l}\text { Open-loop } \\
\text { GRACE-only data assimila- }\end{array}$ & 0.63 & $69.26 \pm 7.38$ & - & - \\
tion & 0.75 & $54.19 \pm 5.79$ & 16.01 & - \\
$\begin{array}{l}\text { Soil moisture data assimila- } \\
\text { tion }\end{array}$ & 0.65 & $66.48 \pm 7.12$ & 3.07 & 21.76 \\
$\begin{array}{l}\text { Joint GRACE-soil moisture } \\
\text { assimilation }\end{array}$ & 0.82 & $51.87 \pm 5.16$ & 23.17 & \\
\hline
\end{tabular}

Furthermore, it is found that this joint data assimilation better reduces the forecast uncertainties. We calculate the average standard deviation (STD) of ensemble members before and after each data assimilation step for all assimilation cases. These ensemble uncertainties 
generally refer to forcing errors that grow by running the model forward in time. While all the cases, as expected, lead to a smaller STD (5.31\% on average) in the analysis steps (after assimilating observations), the least uncertainty is achieved for the joint data assimilation (11.78\% STD reduction). Note that the smaller ensemble STD can also lead to a weaker ensemble spread, however, this is not the case here. The achieved STD reduction means that the method can better propagate ensemble members by improving the spread of forecast ensemble members based on the observations and their associated uncertainties. These results show that data assimilation can improve our understanding of water storage changes. More importantly, monitoring groundwater using reliable information is crucial over South America, where only a few studies have focused on it (e.g., International Groundwater Resources Assessment Centre, 2004; Villar, 2016). Groundwater is a major water resource along with surface storages within the area providing almost $60 \%$ of freshwater use (Villar, 2016). This number is even higher for some countries such as Chile, Peru, Venezuela, Suriname and The Guyanas (Morris et al., 2003). The application of the proposed approach for studying groundwater variations can benefit many of these countries to better monitor groundwater using the enhanced estimates.

As previously mentioned, data assimilation, especially when using GRACE TWS data, can introduce artifacts to other variables. This can be the case not only for different variables in the state vector (e.g., groundwater and soil moisture) but also for non-assimilated variables such as water discharge. To monitor this effect, we compare model water discharge to streamflow in-situ measurements obtained from Hydrology and Geochemistry of the Amazon basin (HYBAM). The monthly in-situ discharge measurements, computed as the sum of the daily discharge, are spatially interpolated to the closest grid points and compared with the estimates at those grid points. Figure 4a shows the average discharge time series over the Amazon basin before and after data assimilation, as well as from in-situ measurements. It can be seen that assimilation of GRACE TWS and soil moisture reduces the misfits between model and in-situ water discharge time series. Furthermore, Figures $4 \mathrm{~b}$ and $4 \mathrm{c}$ present the average scatter plots of the discharge estimates from the open-loop and assimilation compared to the in-situ values. The average correlations between time series are also indicated in the plots, which show the larger agreement between the assimilation results and in-situ streamflow measurements. Data assimilation decreases the RMSE values from $6.47 \mathrm{~cm}$ to $2.88 \mathrm{~cm}$ and increases NSE from 0.47 to 0.71. Assimilation of GRACE TWS and soil moisture, thus, effectively reduces discharge error. This confirms the findings of Syed et al. (2005), who used GRACE TWS and additional 
model-derived fluxes observations to study water discharge over the Amazon basin. Undermining groundwater and moisture storage changes in their experiment, however, led to some degree of discrepancy between the estimated and observed discharge. In contrast, in this study, updating different water compartments including groundwater during the assimilation analysis results in a better agreement between the results and in-situ measurements. In general, Figure 4 indicates that the joint assimilation process not only causes any artifact errors but also improve the discharge estimates (cf. Figure 4).

(a)

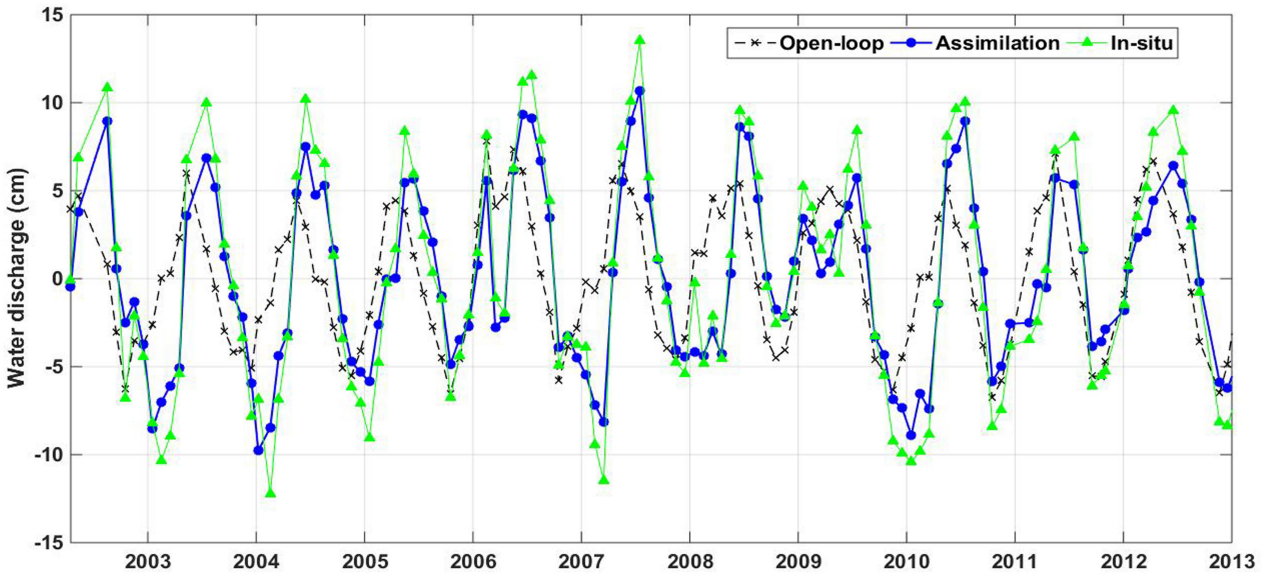

(b)

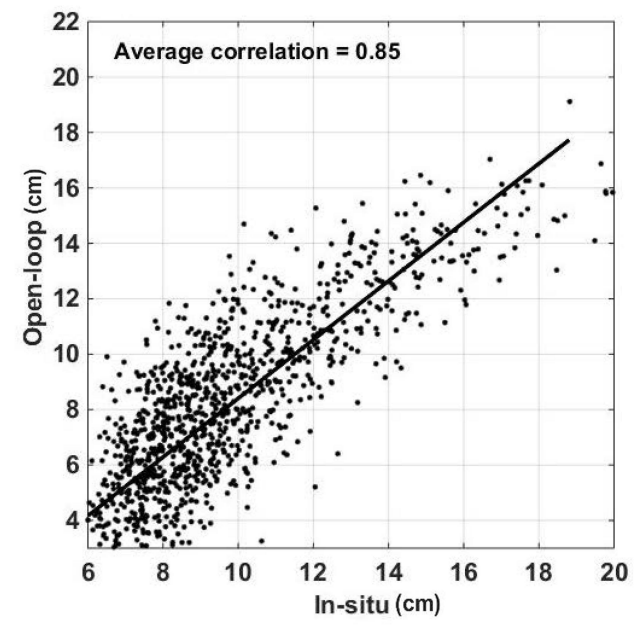

(c)

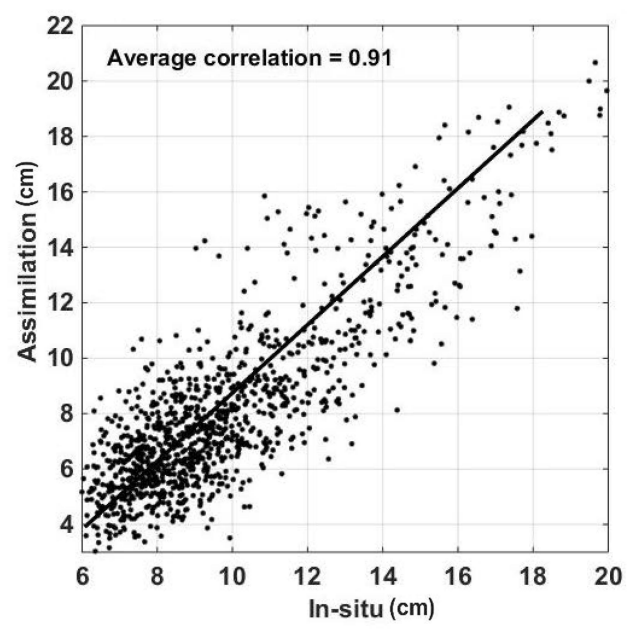

Figure 4: (a) Average discharge time series before and after data assimilation, as well as from in-situ measurements. Scatter plots of average discharge from the open-loop and joint data assimilation with respect to in-situ measurements are presented in (b) and (c), respectively.

To further investigate the effect of data assimilation, we compare the TWS estimates from the joint data assimilation and the open-loop run with precipitation over the Amazon Basin. 
The rationale behind this choice is due to the fact that various studies have reported different droughts (see, e.g., Chen et al., 2009; Frappart et al., 2013) over the basin and a successful data assimilation should be able to capture these phenomena. Figure 5 shows the TWS variations over the basin from the above approaches, as well as precipitation. The average correlation between TWS estimates and precipitation is $0.89, \sim 17 \%$ larger than that of the open-loop run. It can be seen that the data assimilation time series better capture large anomalies such as in 2004 and 2009 reflected also in the precipitation time series. La Niña impact during 2011 (see also Boening et al., 2012) is better captured by the assimilation results. Furthermore, 2005 drought over the Amazon Basin (see, e.g., Chen et al., 2009) is reflected in both open-loop and assimilation results, while the later show a larger amplitude.

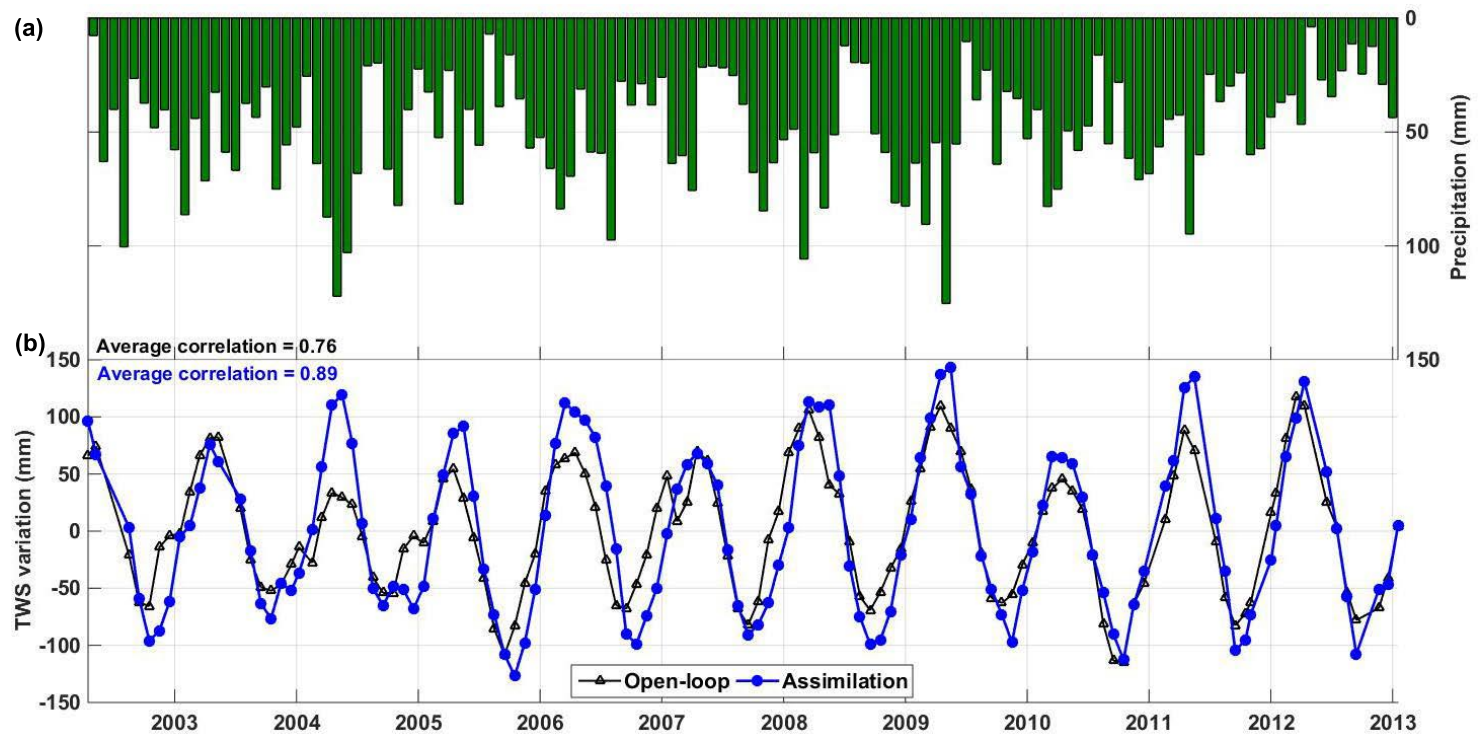

Figure 5: Average precipitation (a) and TWS time series from the open-loop and joint data assimilation (b) over Amazon basin.

Table 2 contains the correlations between the open-loop run and joint data assimilation TWS results and precipitation. The table also reports the correlation improvements in the assimilation results with respect to those of the open-loop against both precipitation as well as ENSO (using Niño 3.4 indicator), as the dominant climate variability index over South America (Tourre et al., 2008; Xavier et al., 2010; Flantua et al., 2016) for each basin. It can be seen that significant improvements are achieved by assimilating remotely sensed TWS and soil moisture observations into W3RA hydrological model. Correlation with both precipitation and 
ENSO over a majority of the basins showcase these improvements. Note that only precipitation correlation improvements are statistically significant. An average correlation between rainfall and TWS anomalies within South America is found to be $0.89, \sim 11 \%$ larger than the openloop results. This indicates that there is a larger agreement between the assimilation results and rainfall over the area than the case of the model simulations without data assimilation. The improvements in terms of correlations with ENSO are different for various basins. For example, larger correlations and corresponding improvements are estimated for Atlantic North Coast (basin 5), Pacific Coast, North Chile (basin 3), Negro (basin 10), Magdalena (basin 4), and Orinoco (basin 12) basins. The reason for this is due to the fact that ENSO effects on precipitation are larger over basins located within the north towards the northeast and the southeast parts of South America and partially over the Amazon basin (Flantua et al., 2016). These larger effects lead to a similar impact on water storage changes that is successfully captured by data assimilation results. In general, larger correlations between the estimated TWS and precipitation over larger basins, e.g., Amazon (basin 15), La Plata (basin 14), and Sao Francisco (basin 13) are also found. This could be due to the ability of GRACE to solve larger basins that better constrain system states during data assimilation.

Table 2: Average correlation between the open-loop and assimilation TWS and precipitation. Correlation improvements are calculated using the increase of correlation between TWS from data assimilation and both precipitation and ENSO with respect to open-loop TWS.

\begin{tabular}{lccccc}
\hline \multirow{2}{*}{ Basins } & \multicolumn{2}{c}{ Correlation to precipitation } & & \multicolumn{2}{c}{ Correlation improvements } \\
\cline { 2 - 3 } \cline { 5 - 6 } Open-loop & assimilation & & Precipitation & ENSO \\
\hline (1) South-east Atlantic & 0.88 & 0.90 & & 2.27 & 3.33 \\
(2) Pacific Coast, Peru & 0.84 & 0.89 & & 5.95 & 7.78 \\
(3) Pacific Coast, North Chile & 0.79 & 0.91 & & 15.19 & 8.17 \\
(4) Magdalena & 0.87 & 0.92 & & 5.75 & 7.23 \\
(5) Atlantic North Coast & 0.91 & 0.95 & & 4.39 & 8.45 \\
(6) Pacific Coast, South Chile & 0.84 & 0.89 & & 5.95 & 3.12 \\
(7) Colorado Basin & 0.78 & 0.91 & & 16.67 & 1.72 \\
(8) Atlantic South Coast & 0.80 & 0.87 & & 8.75 & 2.60 \\
(9) North-east Atlantic & 0.85 & 0.88 & & 3.53 & - \\
(10) Negro Basin & 0.67 & 0.83 & & 23.88 & 11.35 \\
(11) Tocantins & 0.69 & 0.89 & & 28.98 & 4.54 \\
(12) Orinoco & 0.73 & 0.86 & & 17.81 & 9.85 \\
(13) Sao Francisco & 0.92 & 0.92 & & - & 3.06 \\
(14) La Plata & 0.75 & 0.94 & & 25.33 & 5.17 \\
(15) Amazon Basin & 0.92 & 0.94 & & 2.17 & 5.35 \\
\hline
\end{tabular}




\subsection{Water storage changes and climatic impacts}

Average monthly TWS variations over South America from joint data assimilation is shown in Figure 6. Different time spans are used for the averaging period including 2003-2012 (the entire study period) and 2005, 2009, 2010, 2011, and 2012 with remarkable extreme climate event that could potentially affect TWS anomalies. Larger water storage changes can be seen generally for basins located in the northern (e.g, Amazon basin) and southern (e.g., Orinoco and Negro basins) parts of South America. Figure 6 suggests that more water content, and subsequently more TWS variations exist over these areas. This could be due to the abundance of precipitation over these regions (see, e.g., Sanso and Guenni, 1999; Marengo, 2009; Buytaert et al., 2013). On the other hand, basins located in the west and northwest parts, e.g., Magdalena, Pacific Coast-Peru, and Pacific Coast-north Chile basins experience smaller TWS anomalies. The negative water storage anomalies in the northern parts (e.g., Amazon basin) of South America are observed during 2005 and 2010, and also in the southern parts (e.g., Negro basin) during 2009, 2010, 2011, and 2012. These results are supported by the findings of Humphrey et al. (2016) who also demonstrated water storage deficits, e.g., over northern parts (2004-2005), majority parts of Amazon basin (2010), and the western parts of South America (2011). The impact of the 2012 drought, which can be attributed to the anomalous SST in the Atlantic Ocean (Pereira et al., 2014) can clearly be seen within the eastern and southern parts of South America (see also Sun et al., 2016). Furthermore, El Niño effect in 2009 (Tedeschi et al., 2013) and La Niña effect in 2011 (Boening et al., 2012) can be seen through large anomalies, e.g., in the north, northeast, and southern parts.

To better analyze spatio-temporal variations of sub-surface water storages within South America, PCA is applied to groundwater and soil moisture results. Figure 7 shows the first three dominant modes. Furthermore, rainfall variations both spatially and temporally are investigated to explore their connections to water storage variations. Major water storages can be found from central to northern parts of South America, areas with rainfall patterns dominated by ENSO phenomena (Carrillo et al., 2010). This shows a larger amount of storages over the area mainly due to more rainfall. Considerable soil moisture content variations are found over North-east Atlantic (mode 2 and mode 3) and La Plata (mode 3). Larger groundwater variations can also be seen in Amazon and La Plata. To a lesser degree, the Orinoco and Atlantic North Coast basins contain large signal variations both for groundwater and soil moisture. It can also be seen that both groundwater and soil moisture variations modestly follow the same 
2003-2012

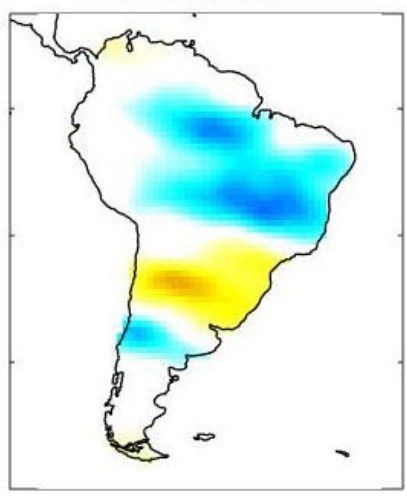

2010

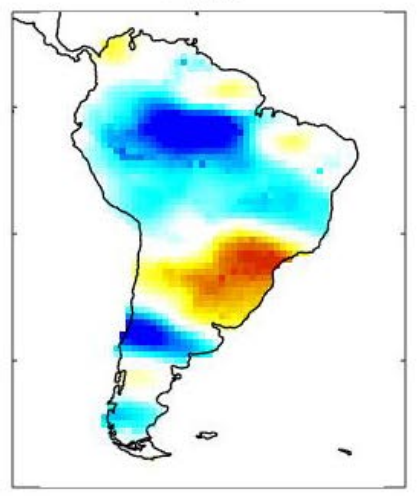

2005

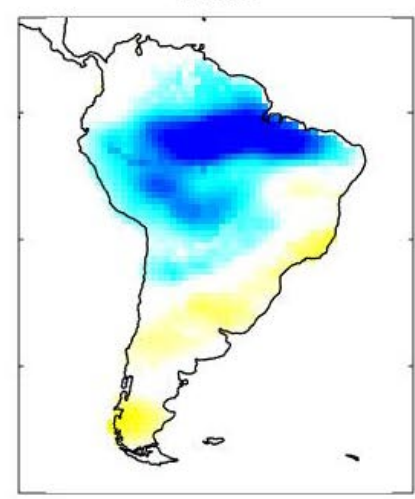

2011
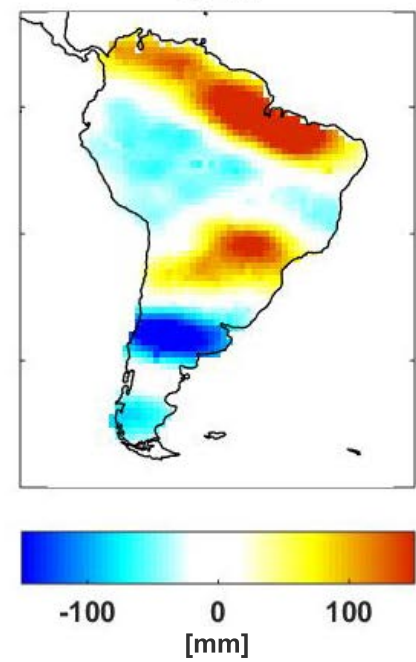

2009

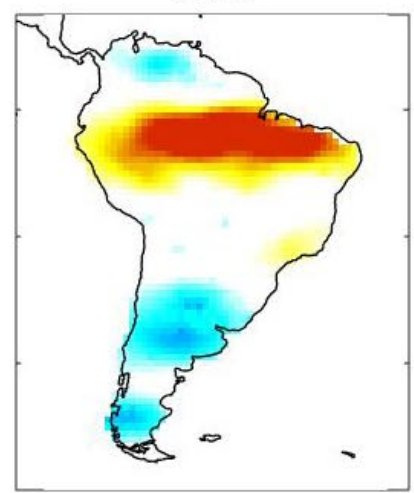

2012

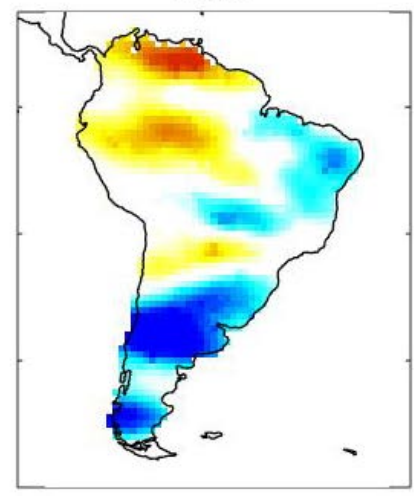

Figure 6: Average monthly TWS variations from data assimilation for different time periods.

pattern except for mode 3, where negative variations exist in the soil moisture map over the south-eastern parts while the negative variations in groundwater map can be found over the central to northern parts. The positive anomalies over northern parts in soil moisture variations, as it will be shown, matches precipitation patterns in the same areas. This suggests that between the two water compartments, soil moisture variations follow precipitation more closely, whereas groundwater changes which can largely be affected by non-climatic factors, e.g., anthropogenic impacts. In general, based on these maps, more sub-surface water variabilities exist over the central towards northern and western parts of the continent compared to the south-western areas.

In terms of temporal variations, the first three extracted principal components $(\mathrm{PC})$ of 
groundwater and soil moisture are also demonstrated in Figure 7. The time series of both water storages largely depict annual effects dominant over the majority of South America's parts including its central to the north. These parts are also affected by the Strong influence of La Niña for 2010-2011, as well as El Niño effect in 2008-2009. Negative trends in groundwater are captured by PC2 over the northeast and central toward western parts before 2006, between 2007 and 2009, and also between 2010 and 2012. Such trends cannot be seen in soil moisture time series suggesting that non-climatic impacts such as the water used for power generation in Brazil (Sun et al., 2016) could possibly be responsible for the groundwater depletion. The negative soil moisture variations (mode 2) in the central part can be attributed to the multiple drought conditions, e.g., in the La Plata basin (2008-2009, Abelen et al., 2015). This soil moisture reduction was also reported by Escobar (2015) over the Amazon basin, which could be due to the anthropogenic impact on forest conservation. Dry events from 2012 to 2014 suggested by Humphrey et al. (2016) and Getirana (2016) can be seen in the northern and eastern parts of the South America, also reflected in groundwater and soil moisture time series (PC3 in Figure 7). Considerable anomalies are found in 2006-2007 and 2010 from groundwater and soil moisture mostly over the northern and eastern parts, which could be attributed to extreme climatic events in the same periods. On the other hand, a negative anomaly is detected in 2004 by both water storages. The 2005 dry condition effects on soil moisture is captured by soil moisture's second mode, which confirms the same impacts presented in Figure 6. The third mode of soil moisture time series depicts a negative anomaly for the period of 2002-2006 mostly over Negro basin, which, as will be shown, matches the third precipitation mode. El Niño effect in 2009 causes groundwater negative anomaly in both modes 2 and 3 (see also Figure 6) affecting the central and eastern parts. Similar negative anomalies can also be seen in 2006 for groundwater, and in 2005 for soil moisture. A big part of these variations (e.g., over 2005, 2009-2012) can be related to climate variabilities while some of them, e.g., groundwater negative trends between 2003 and 2006 and also 2007 and 2009, can be due to non-climate factors such as human usage and irrigations. 

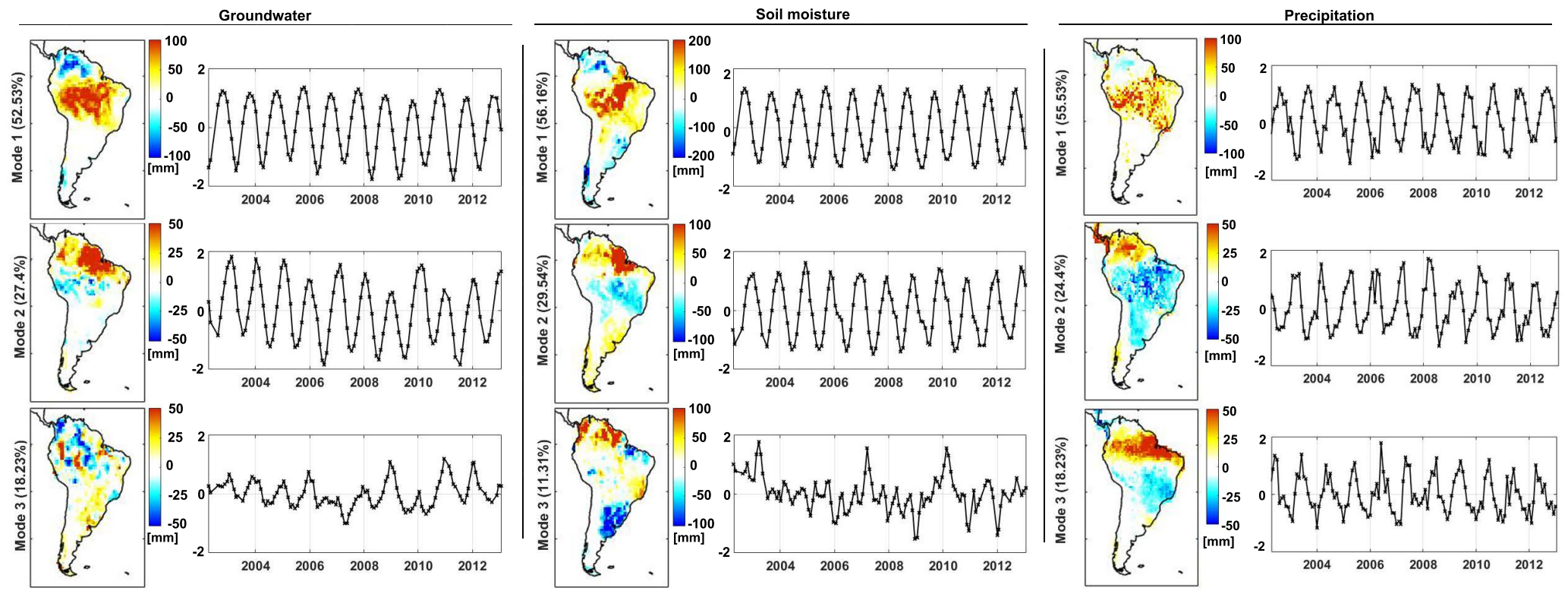

Figure 7: Three first modes of spatial distribution and temporal variations from the application of PCA on groundwater, soil moisture, and precipitation.

A major rainfall pattern is found over the central toward northern parts of South America, especially Amazon basin, where most of groundwater and soil moisture variations are explored. While the spatiotemporal distributions of rainfall are highly matched to those of groundwater and soil moisture in the first mode, the precipitation second mode is more correlated to that of soil moisture. This, as expected, indicates that precipitation has larger influence on soil moisture variations while groundwater can be largely affected by other factors (e.g., water usages). Next, Atlantic North Coast, La Plata, and Negro basins indicate larger signals in contrast to south-western basins, e.g., Pacific Coast, South Chile and Atlantic South Coast. Similar to groundwater and soil moisture mode 1, rainfall time series in Figure 7 also displays strong seasonal variations. In contrast to the negative anomalies in groundwater second mode time series, precipitation mode 2 does not show similar trends. However, both modes 2 and 3 indicate a rainfall decline after 2012 mostly affecting the eastern toward northern parts (see, e.g., Humphrey et al., 2016; Getirana, 2016). Similar to water storage time series, the La Niña effect can be observed for 2010-2011 (Boening et al., 2012). Large anomalies are also captured in 2005, 2006, and 2010, which considerably impacts water storages. El Niño effect in 2009 can also be seen in the second mode, which also affected groundwater and soil moisture variations within the central and south-eastern parts. A negative anomaly can be seen before 2004 in the 
mode 3, which can be related to a weak El Niño causing negative anomalies of precipitation during the wet season (Juarez et al., 2009). Sun et al. (2016) suggested that this period exhibits months drier than the normal seasonal cycle of TWS due to the rainfall rates lower than the average. These prolonged reductions in rainfall can explain similar negative anomalies that occurred in groundwater and soil moisture time series seen.

Average trends for groundwater and soil moisture from the open-loop run and joint assimilation are presented in Table 3 for the basins. To this end, the modified Mann-Kendall trend test (Yue and Wang, 2002) is applied on deseasonalized time series. Note that the autocorrelation analysis is also used to compute an effective sample size and to correct the Mann-Kendall statistic. The trends when the p-values fall below 0.05 are considered statistically significant. It is worth mentioning that in addition to groundwater and soil moisture, the basin averaged precipitation time series are also considered here to investigate the climatic impacts on water storage changes. It can be seen that the application of data assimilation in many cases causes changes in either amplitude of trends or their signs. For example, over the Orinoco, the signs of variations become negative after data assimilation while these remained the same for La Plata with different amplitudes. For some other basins like South-east Atlantic, the trend values are close before and after data assimilation, which could be due to the smaller impacts of data assimilation.

It is also evident that there are larger agreements between precipitation and soil moisture trends. This further indicates that soil moisture changes mostly rely on rainfall pattern within South America. The mismatch between precipitation and groundwater trend signs over most of the basins, e.g., Pacific Coast, South Chile, Orinoco, South-east Atlantic and Colorado, suggests that non-climatic factors mostly influence the groundwater changes. This, in all of the cases, leads to a groundwater depletion while precipitation shows neither negative nor statistically significant trends. Nevertheless, negative trends are found in precipitation, soil moisture, and also groundwater over La Plata, Atlantic North Coast, Atlantic South Coast, and North-East Atlantic. Even though one can conclude that a majority of groundwater depletion over these basins can be caused by the precipitation decline, human impacts can still be an effective factor whereas assessing their contributions require additional information.

From Table 3, negative groundwater trends can be seen in most of the basins. For example, Sao Francisco and North-east Atlantic basins show the largest groundwater depletion compared to the other basins. This can be attributed to the fact that these basins have been under an 
Table 3: Statistics of groundwater and soil moisture variation rates (mm/year) from the open-loop run and joint data assimilation. The statistically significant values at $95 \%$ confidence limit are demonstrated in bold.

\begin{tabular}{|c|c|c|c|c|c|}
\hline \multirow[b]{2}{*}{ Basins } & \multicolumn{2}{|c|}{ Open-loop } & \multicolumn{2}{|c|}{ Assimilation } & \multirow[b]{2}{*}{ Precipitation } \\
\hline & Groundwater & Soil moisture & Groundwater & Soil moisture & \\
\hline (1) South-east Atlantic & -0.37 & -0.44 & -0.57 & +0.44 & +0.09 \\
\hline (2) Pacific Coast, Peru & -0.10 & -0.13 & -1.09 & +0.12 & +0.06 \\
\hline (3) Pacific Coast, North Chile & - & - & -0.03 & -0.05 & +0.13 \\
\hline (4) Magdalena & -0.02 & +0.16 & +0.62 & +0.05 & -0.01 \\
\hline (5) Atlantic North Coast & +0.02 & +0.01 & -0.17 & -0.23 & -0.22 \\
\hline (6) Pacific Coast, South Chile & - & -0.07 & -1.52 & -0.76 & +0.22 \\
\hline (7) Colorado Basin & -0.25 & +0.20 & -0.21 & +0.23 & +0.28 \\
\hline (8) Atlantic South Coast & -0.06 & & -0.57 & -0.27 & -0.12 \\
\hline (9) North-east Atlantic & +0.26 & +0.36 & -0.98 & -0.47 & -0.17 \\
\hline (10) Negro Basin & -0.04 & - & -0.21 & - & - \\
\hline (11) Tocantins & +0.02 & +0.07 & +0.54 & +0.03 & +0.02 \\
\hline (12) Orinoco & +0.17 & +0.35 & -0.53 & +0.09 & +0.01 \\
\hline (13) Sao Francisco & -0.07 & -0.06 & -0.47 & -0.24 & -0.03 \\
\hline (14) La Plata & -0.89 & +0.09 & -1.09 & -0.14 & -0.10 \\
\hline (15) Amazon Basin & +0.05 & +0.14 & +0.07 & -0.02 & +0.05 \\
\hline
\end{tabular}

unprecedented water depletion as can be inferred from the studies of Getirana (2016) and Sun et al. (2016). Trend signs of soil moisture changes generally follow precipitation's. This, however, is different for some basins such as Pacific Coast, South Chile and Amazon. This mismatch over the Amazon basin can be explained by the fact that anthropogenic impacts on forest conservation results in soil moisture decline (see, e.g., Escobar, 2015). Similar negative trends are observed for both groundwater and soil moisture over La Plata, and also groundwater over Orinoco (Ramirez et al., 2017), which can be attributed to deforestation and excessive water use that have also been reported, e.g., by Pereira et al. (2011) for La Plata and Ramirez et al. (2017) for Orinoco basins (see also Frappart et al., 2015). There are also discrepancies between soil moisture and groundwater trend signs, e.g., over La Plata and Pacific Coast, North Chile. While the rate of the changes are smaller over Pacific Coast North Chile, La Plata, which are located in the most populated areas of South America, they have larger negative groundwater trends that could possibly be due to increased agricultural and livestock water usage in the basin (see also Chen et al., 2010). For some of the basins (e.g., the Amazon basin), the trends are not significant, especially the soil moisture and precipitation changes (e.g., over the Tocantins). In general, the annual rate of groundwater anomaly is -0.24 (mm/year) in South America, suggesting its depletion between 2002 and 2013. This could be due to climatic impacts (e.g., droughts, see, e.g., Bates et al., 2008; Chen et al., 2010; Treidel et al., 2011; Getirana, 2016; Sun et al., 2016) and/or exponential increase of agriculture and industrial activities (Bocanegra et al., 2010). This negative trend is very important due to its effects on South America's water and 
its use for agriculture. Groundwater is a major source of irrigation over most of the countries within South America such as major rice-growing regions of North Eastern Argentina, South Brazil and Uruguay (Herring, 2012). Besides, groundwater depletion can largely increase water quality challenges (e.g., Arsenic growth) as a potential issue over South America (see, e.g., Munoz et al., 2002; Perez-Carrera and Cirelli, 2009; Herring, 2012).

\section{Conclusion}

Multimission satellite datasets including Terrestrial water storages (TWS) from the Gravity Recovery And Climate Experiment (GRACE) satellite mission and soil moisture products from the Advanced Microwave Scanning Radiometer - Earth Observing System (AMSR-E) and Soil Moisture and Ocean Salinity (SMOS) are assimilated into the World-Wide Water Resources Assessment (W3RA) model using the Ensemble Square-Root Filter (EnSRF) to increase the model performance for estimating groundwater and soil moisture over South America. The application of joint data assimilation causes improvements in W3RA estimates against groundwater in-situ measurements. This effect could clearly be seen for TWS estimates and importantly for groundwater simulations, which emphasize the potentials of assimilating remotely sensed products to increase the reliability of the W3RA hydrological model. We further investigate the correlation between assimilation results and precipitation from the Tropical Rainfall Measuring Mission (TRMM), as well as El Niño/Southern Oscillation (ENSO). The results indicate that assimilation TWS are more correlated to the TRMM rainfall and ENSO data compared to open-loop TWS estimates. Both of these assessments demonstrate the capability of data assimilation for improving model simulations of water resources over South America. Based on the results, the new information of groundwater and soil moisture are more reliable, which can be used for water management and agriculture objectives. From the application of principal component analysis (PCA) on water storage variations within South America and its 15 major basins, more soil moisture and groundwater anomalies are found over central toward northern and western parts of South America. Based on the results, a negative trend for groundwater is observed over most parts of South America. Negative trends are found for groundwater and to a lesser degree for soil moisture variations over the majority of the studied basins. This study shows that application of data assimilation can successfully improve our understanding of water storage changes. Nevertheless, more investigations are still needed to fully assess the approach's performance, e.g., by applying new observations such as GRACE 
follow-on and Surface Water and Ocean Topography (SWOT), sensitivity analysis regarding data uncertainties, and the impacts of GRACE data assimilation on non-assimilated variables.

\section{Acknowledgement}

We would like to thank Dr. Augusto Getirana for providing the surface water storage data and also his review suggestions, which contributed to the improvement of this study. M. Khaki is grateful for the research grant of Curtin International Postgraduate Research Scholarships (CIPRS)/ORD Scholarship provided by Curtin University (Australia). J. Awange is grateful for the Brazilian Science Without Borders Program/CAPES Grant No. 88881.068057/201401. This work is a TIGeR publication.

\section{References}

Abelen, S., Seitz, F., Abarca-del-Rio, R., Gntner, A., (2015). Droughts and Floods in the La Plata Basin in Soil Moisture Data and GRACE. Remote Sens., 7, 7324-7349, http://dx.doi.org/10.3390/rs70607324.

Anderson, J., (2001). An Ensemble Adjustment Kalman Filter for Data Assimilation. Mon. Wea. Rev., 129, 28842903, http://dx.doi.org/10.1175/15200493(2001)129¡2884:AEAKFF ¿2.0.CO;2.

Anderson, M.C., Norman, J.M., Mecikalski, J.R., Otkin, J.A., Kustas, W.P., (2007). A climatological study of evapotranspiration and moisture stress across the continental United States based on thermal remote sensing: 1. Model formulation. J. Geophys. Res. 112 (D10117). http://dx.doi.org/10.1029/2006JD007506.

Altaf, M.U., Butler, T., Mayo, T., Luo, X., Dawson, C., Heemink, A.W., Hoteit, I., (2014). A Comparison of Ensemble Kalman Filters for Storm Surge Assimilation, Monthly Weather Review, 142:8, 2899-2914.

Alsdorf, D.E., Rodriguez, E., Lettenmaier, D.P., (2007). Measuring surface water from space, Rev. Geophys., 45, RG2002, http://dx.doi.org/10.1029/2006RG000197.

Bates, B.C., Kundzewicz, Z.W., Wu, S., Palutikof, J.P., (2008). Climate change and water, Chapter 3 Linking climate change and water resources: impacts and responses, IPCC Secretariat, Geneva, 210 pp. 
Beck, H.E., van Dijk, A.I.J.M., de Roo, A., Miralles, D.G., McVicar, T.R., Schellekens, J., Bruijnzeel, L.A., (2016). Global-scale regionalization of hydrologic model parameters, Water Resour. Res., 52, 35993622, http://dx.doi.org/10.1002/2015WR018247.

Bennett, A.F., (2002). Inverse Modeling of the Ocean and Atmosphere, 234 pp., Cambridge Univ. Press, New York.

Bertino, L., Evensen G., Wackernagel, H., (2003). Sequential Data Assimilation Techniques in Oceanography, International Statistical Review, Vol. 71, No. 2 (Aug., 2003), pp. 223-241.

Bharati, L., Rodgers, C., Erdenberger, T., Plotnikova, M., Shumilov, S., Vlek, P., Martin, N., (2008). Integration of economic and hydrologic models: Exploring conjunctive irrigation water use strategies in the Volta Basin, Agricultural Water Management, Volume 95, Issue 8, 2008, Pages 925-936, ISSN 0378-3774, http://dx.doi.org/10.1016/j.agwat.2008.03.009.

Boening, C., Willis, J.K., Landerer, F.W., Nerem, R.S., Fasullo, J., (2012). The 2011 La Nia: So strong, the oceans fell, Geophys. Res. Lett., 39, L19602, http://dx.doi.org/10.1029/2012GL053055.

Bocanegra, E., Silva, G.C., Custodio, E., Manzano, M., Montenegro, S., (2010). State of knowledge of coastal aquifer management in South America, Hydrogeology Journal, Volume 18, Issue 1, pp 261267, http://dx.doi.org/10.1007/s10040-009-0520-5.

Buytaert, W., Breuer, L., Buytaert, W., Breuer, L., et al., (2013). Water resources in South America: sources and supply, pollutants and perspectives, Symposium on Understanding Freshwater Quality Problems in a Changing World / Joint Assembly of IAHS, IAPSO and IASPEI, Publisher: INT ASSOC HYDROLOGICAL SCIENCES, Pages: 106-113, ISSN: 0144-7815.

Dillon, M.E., Skabar, Y.G., Ruiz, J., Kalnay, E., Collini, E.A., Echevarra, P., Saucedo, M., Miyoshi, T., Kunii, M., (2016). Application of the WRF-LETKF Data Assimilation System over Southern South America: Sensitivity to Model Physics. Wea. Forecasting, 31, 217236, https://doi.org/10.1175/WAF-D-14-00157.1.

Betts, A.K., Ball, J.H., Beljaars, A.C.M., Miller, M.J., Viterbo, P.A., (1996). The land surfaceatmosphere interaction: A review based on observational and global modeling perspectives. J. Geophys. Res., 101 (D3), 72097225. 
Cabrera, J., Yupanqui, R.T., Rau, P., (2016). Validation of TRMM Daily Precipitation Data for Extreme Events Analysis. The Case of Piura Watershed in Peru, Procedia Engineering, Volume 154, 2016, Pages 154-157, ISSN 1877-7058, http://dx.doi.org/10.1016/j.proeng.2016.07.436.

Carrillo, C.M., (2010). The rainfall over tropical South America generated by multiple scale processes, Graduate Theses and Dissertations. 11536, http://lib.dr.iastate.edu/etd/11536.

Ceccherini, G., Ameztoy, I., Hernndez, C., Moreno, C., (2015). HighResolution Precipitation Datasets in South America and West Africa based on Satellite-Derived Rainfall, Enhanced Vegetation Index and Digital Elevation Model, Remote Sensing, 7, 64546488, http://dx.doi.org/10.3390/rs70506454.

Chen, J.L., Wilson, C.R., Famiglietti, J.S., Rodell, M., (2007). Attenuation effect on seasonal basin-scale water storage changes from GRACE time-variable gravity. Journal of Geodesy, 81, 4, 237245, http://dx.doi.org/10.1007/s00190-006-0104-2.

Chen, J.L., Wilson, C.R., Tapley, B.D., Yang, Z.L., Niu, G.Y., (2009). 2005 drought event in the Amazon River basin as measured by GRACE and estimated by climate models, J. Geophys. Res., 114, B05404, http://dx.doi.org/10.1029/2008JB006056.

Chen, J.L., Wilson, C.R., Tapley, B.D., Longuevergne, L., Yang, Z.L., Scanlon, B.R., (2010). Recent La Plata basin drought conditions observed by satellite gravimetry, J. Geophys. Res., 115, D22108, http://dx.doi.org/10.1029/2010JD014689.

Cheng, M.K., Tapley, B.D., (2004). Variations in the Earth's oblateness during the past 28 years. Journal of Geophysical Research, Solid Earth, 109, B09402. http://dx.doi.org/10.1029/2004JB003028.

Chou, S.C., Tanajura, C.A.S., Xue, Y., Nobre, C.A., (2002). Validation of the coupled Eta/SSiB model over South America, J. Geophys. Res., 107(D20), 8088, http://dx.doi.org/10.1029/2000JD000270.

Condom, T., Rau, P., Espinoza, J.C., (2011). Correction of TRMM 3B43 monthly precipitation data over the mountainous areas of Peru during the period 19982007. Hydrol. Process., 25: 19241933, http://dx.doi.org/10.1002/hyp.7949. 
De Jeu, R.A.M., Owe, M., (2003). Further validation of a new methodology for surface moisture and vegetation optical depth retrieval. Int J Remote Sens 24:45594578, http://dx.doi.org/10.1080/0143116031000095934.

De Jeu, R.A.M., Wagner, W., Holmes, T.R.H., Dolman, A.J., van de Giesen , N.C., Friesen J., (2008) Global Soil Moisture Patterns Observed by Space Borne Microwave Radiometers and Scatterometers, Surveys in Geophysics,Volume 29, Issue 45, pp 399420, http://dx.doi.org/10.1007/s10712-008-9044-0.

De Paiva, R.C.D.R.C.D., Buarque, D.C.D.C., Collischonn, W., Bonnet, M.-P.M.P., Frappart, F., Calmant, S., Bulhes Mendes, C.A.C.A., (2013). Large-scale hydrologic and hydrodynamic modeling of the Amazon River basin. Water Resour. Res., 49, 1226-1243, http://dx.doi.org/10.1002/wrcr.20067.

Döll, P., Kaspar, F., Lehner, B., (2003). A global hydrological model for deriving water availability indicators: model tuning and validation, J. Hydrol., 270, 105134.

Draper, C.S., Mahfouf, J.-F., Walker, J.P., (2009), An EKF assimilation of AMSRE soil moisture into the ISBA land surface scheme, J. Geophys. Res., 114, D20104, http://dx.doi.org/10.1029/2008JD011650.

Dumedah, G., Walker, J.P., Merlin, O., (2015). Root-zone soil moisture estimation from assimilation of downscaled Soil Moisture and Ocean Salinity data, Advances in Water Resources, Volume 84, Pages 14-22, ISSN 0309-1708, https://doi.org/10.1016/j.advwatres.2015.07.021.

Eicker, A., Schumacher, M., Kusche, J., Dll, P., Mller-Schmied, H., (2014). Calibration/data assimilation approach for integrating GRACE data into the WaterGAP global hydrology model (WGHM) using an ensemble Kalman filter: first results, SurvGeophys, 35(6):12851309. http://dx.doi.org/10.1007/s10712-014-9309-8.

Elbern, H., Schmidt, H., (2001). Ozone episode analysis by fourdimensional variational chemistry data assimilation, J. Geophys. Res., 106, 35693590.

Erfanian, A., Wang, G., Fomenko, L., (2017). Unprecedented drought over tropical South America in 2016: significantly under-predicted by tropical SST, Scientific Reports 7, Article number: 5811, http://dx.doi.org/10.1038/s41598-017-05373-2. 
Escobar, H., (2015). Drought triggers alarms in Brazils biggest metropolis, Science 2015, 347, 812812.

Evensen, G., (2003). The ensemble Kalman filter: Theoretical formulation and practical inplementation, Ocean Dynamics, 53, 343367, http://dx.doi.org/10.1007/s10236-003-0036-9.

Evensen, G., (2007). Data Assimilation: The Ensemble Kalman Filter, Springer, 279 pp.

Flantua, S.G.A., Hooghiemstra, H., Vuille, M., Behling, H., Carson, J.F., Gosling, W. D., Hoyos, I., Ledru, M. P., Montoya, E., Mayle, F., Maldonado, A., Rull, V., Tonello, M.S., Whitney, B.S., Gonzlez-Arango, C., (2016). Climate variability and human impact in South America during the last 2000 years: synthesis and perspectives from pollen records, Clim. Past, 12, 483-523, https://doi.org/10.5194/cp-12-483-2016.

Frappart, F., Seoane, L., Ramillien, G., (2013). Validation of GRACE-derived terrestrial water storage from a regional approach over South America. Remote Sensing of Environment, Elsevier, 2013, 137, pp.69-83.

Frappart, F., Papa, F., Malbeteau, Y., Len, J.G., Ramillien, G., Prigent, C., Seoane, L., Seyler, F., Calmant, S. Surface Freshwater Storage Variations in the Orinoco Floodplains Using Multi-Satellite Observations. Remote Sens. 2015, 7, 89-110.

Garner, T.W., Wolf, R.A., Spiro, R.W. , Thomsen, M.F., (1999). First attempt at assimilating data to constrain a magnetospheric model, J. Geophys. Res., 104(A11), 2514525152, http://dx.doi.org/10.1029/1999JA900274.

Garreaud, R.D., Vuille M., Compagnucci, R., Marengo, J., (2008). Presentday South American climate, Paleogeogr. Palaeoclimatol. Palaeoecol., http://dx.doi.org/10.1016/j.palaeo.2007.10.032.

Getirana, A.B., Yamazaki, D., Decharme, B., Papa, F., Mognard, N., (2012). The Hydrological Modeling and Analysis Platform (HyMAP):Evaluation in the Amazon basin. Journal of Hydrometeorology, 13, 16411665, https://doi.org/10.1175/JHM-D-12-021.1.

Getirana, A., Dutra, E., Guimberteau, M., Kam, J., Li, H., Decharme, B., Zhang, Z., Ducharne, A., Boone, A., Balsamo, G., Rodell, M., Toure, A.M., Xue, Y., Drapeau, G., Arsenault, K., Kumar, S.V., Leung, L.R., Peters-Lidard, C., Ronchail, J., Sheffield, J., (2014). Water balance 
in the Amazon basin from a land surface model ensemble. Journal of Hydrometeorology, 15, 2586-2614, http://dx.doi.org/10.1175/JHM-D-14-0068.1

Getirana, A., (2016). Extreme water deficit in Brazil detected from space. Journal of Hydrometeorology, 17, 591-599, http://dx.doi.org/10.1175/JHM-D-15-0096.1.

Getirana, A., Kumar, S., Girotto, M., Rodell, M., (2017). Rivers and floodplains as key components of global terrestrial water storage variability. Geophysical Research Letters, 44, https://doi.org/10.1002/2017GL074684.

Girotto, M., G. J. M. De Lannoy, R. H. Reichle, and M. Rodell (2016), Assimilation of gridded terrestrial water storage observations from GRACE into a land surface model, Water Resour. Res., 52, 41644183, http://dx.doi.org/10.1002/2015WR018417.

Girotto, M., G. J. M. De Lannoy, R. H. Reichle, M. Rodell, C. Draper, S. N. Bhanja, and A. Mukherjee (2017), Benefits and pitfalls of GRACE data assimilation: A case study of terrestrial water storage depletion in India, Geophys. Res. Lett., 44, 41074115, http://dx.doi.org/10.1002/2017GL072994.

de Goncalves, L.G., Shuttleworth, W.J., Vila, D., Larroza, E., Bottino, M.J., Herdies, D.L., Aravequia, J.A., De Mattos, J.G., Toll, D.L., Rodell, M., Houser, P., (2009). The South American Land Data Assimilation System (SALDAS) 5-Yr Retrospective Atmospheric Forcing Datasets. J. Hydrometeor., 10, 9991010, https://doi.org/10.1175/2009JHM1049.1.

Grau, H.R., Aide, M., (2008). Globalization and land-use transitions in Latin America. Ecology and Society, 13(2), 16, www.ecologyandsociety.org/vol13/iss2/art16/.

Grimson, R., Montroull, N., Saurral, R., Vasquez, P., Camilloni, I., (2013). Hydrological modelling of the Iber Wetlands in southeastern South America, Journal of Hydrology, Volume 503, Pages 47-54, ISSN 0022-1694, https://doi.org/10.1016/j.jhydrol.2013.08.042.

Herring, M., (2012). Agriculture and Biodiversity: Opportunities for a Better Marriage. Rice Growers Association Annual Conference, One Tree, NSW.

Hoteit, I., Pham, D.T., Triantafyllou, G., Korres, G., (2008). A new approximate solution of the optimal nonlinear filter for data assimilation in meteorology and oceanography, Monthly Weather Review, 136, 317-334. 
Hoteit, I., Luo, X., Pham, D.T., (2012). Particle Kalman Filtering: A Nonlinear Bayesian Framework for Ensemble Kalman Filters, Monthly Weather Review, 140:2, 528-542.

Hoteit, I., Pham, D.T., Gharamti, M. E., Luo, X., (2015). Mitigating Observation Perturbation Sampling Errors in the Stochastic EnKF, Monthly Weather Review, 143:7, 2918-2936.

Houborg, R., Rodell, M., Li, B., Reichle, R., Zaitchik, B.F., (2012). Drought indicators based on modelassimilated Gravity Recovery and Climate Experiment (GRACE) terrestrial water storage observations, Water Resour. Res., 48, W07525, http://dx.doi.org/10.1029/2011WR011291.

Huffman, G., Bolvin, D., (2012). TRMM and other data precipitation data set documentation. Mesoscale Atmospheric Processes Laboratory, NASA Goddard Space Flight Center and Science Systems and Applications, Inc.

Humphrey, V., Gudmundsson, L., Seneviratne, S.I., (2016). Assessing Global Water Storage Variability from GRACE: Trends, Seasonal Cycle, Subseasonal Anomalies and Extremes, Surv Geophys, 37: 357, https://doi.org/10.1007/s10712-016-9367-1.

International Groundwater Resources Assessment Centre, (2004). Graphic groundwater and climate change, International Groundwater Resources Assessment Centre, UNESCO, International Hydrological Programme, Division of water sciences, www.graphicnetwork.net.

Jackson, T., Bindlish, R., (2012). Validation of Soil Moisture And Ocean Salinity (SMOS) soil moisture over watershed networks in the US, IEEE Trans. Geosci. Remote Sens., 50, 15301543.

Jacquette, E., Al Bitar, A., Mialon, A., Kerr, Y., Quesney, A., Cabot, F., et al., (2010). SMOS CATDS level 3 global products over land. In C. M. U. Neale, A. Maltese (Eds.), Remote Sensing for Agriculture, Ecosystems, and Hydrology XII. volume 7824 of Proceedings of SPIE-The International Society for Optical Engineering. Conference on Remote Sensing for Agriculture, Ecosystems, and Hydrology XII, Toulouse, France.

Juarez, R.I., Li, W., Fu, R., Fernandes, K., de Oliveira Cardoso, A., (2009). Comparison of Precipitation Datasets over the Tropical South American and African Continents. J. Hydrometeor., 10, 289299, https://doi.org/10.1175/2008JHM1023.1. 
Khaki, M., Hoteit, I., Kuhn, M., Awange, J., Forootan, E., van Dijk, A.I.J.M., Schumacher M., Pattiaratchi, C., (2017a). Assessing sequential data assimilation techniques for integrating GRACE data into a hydrological model, Advances in Water Resources, Volume 107, Pages 301-316, ISSN 0309-1708, http://dx.doi.org/10.1016/j.advwatres.2017.07.001.

Khaki, M., Schumacher, M., J., Forootan, Kuhn, M., Awange, E., van Dijk, A.I.J.M., (2017b). Accounting for Spatial Correlation Errors in the Assimilation of GRACE into Hydrological Models through localization, Advances in Water Resources, Available online 1 August 2017, ISSN 0309-1708, https://doi.org/10.1016/j.advwatres.2017.07.024.

Khaki, M., Ait-El-Fquih, B., Hoteit, I., Forootan, E., Awange, J., Kuhn, M., (2017c). A Twoupdate Ensemble Kalman Filter for Land Hydrological Data Assimilation with an Uncertain Constraint, Journal of Hydrology, Available online 25 October 2017, ISSN 0022-1694, https://doi.org/10.1016/j.jhydrol.2017.10.032.

Khaki, M., Forootan, E., Kuhn, M., Awange, J., Papa, F., Shum, C.K., (2018a). A Study of Bangladesh's Sub-surface Water Storages Using Satellite Products and Data Assimilation Scheme. Science of The Total Environment, 625:963-977, https://doi.org/10.1016/j.scitotenv.2017.12.289.

Khaki, M., Forootan, E., Kuhn, M., Awange, J., van Dijk, A.I.J.M., Schumacher, M., Sharifi, M.A., (2018b). Determining Water Storage Depletion within Iran by Assimilating GRACE data into the W3RA Hydrological Model. Advances in Water Resources, 114:1-18, https://doi.org/10.1016/j.advwatres.2018.02.008.

Khaki, M., Hamilton, F., Forootan, E., Hoteit, I., Awange, J., Kuhn, M., (2018c). Nonparametric Data Assimilation Scheme for Land Hydrological Applications, Water Resour. Res.. https://doi.org/10.1029/2018WR022854.

Khaki, M., Ait-El-Fquih, B., Hoteit, I., Forootan, E., Awange, J., Kuhn, M., (2018d). Unsupervised ensemble Kalman filtering with an uncertain constraint for land hydrological data assimilation, In Journal of Hydrology, Volume 564, Pages 175-190, ISSN 0022-1694, https://doi.org/10.1016/j.jhydrol.2018.06.080.

Khaki, M., Forootan, E., Kuhn, M., Awange, J., Longuevergne, L., Wada, W., (2018e). Efficient 
Basin Scale Filtering of GRACE Satellite Products, In Remote Sensing of Environment, Volume 204, Pages 76-93, ISSN 0034-4257, https://doi.org/10.1016/j.rse.2017.10.040.

Kolassa, J., Reichle, R.H., Liu, Q., Cosh, M., Bosch, D.D., Caldwell, T.G., Colliander, A., Holifield Collins, C., Jackson, T.J., Livingston, S.J., Moghaddam, M., Starks, P.J., (2017). Data Assimilation to Extract Soil Moisture Information from SMAP Observations. Remote Sens., 9, 1179.

Kourgialas, N.N., Karatzas, G.P., (2015). A modeling approach for agricultural water management in citrus orchards: cost-effective irrigation scheduling and agrochemical transport simulation, Environ Monit Assess., 187(7):462. https://doi.org/10.1007/s10661-015-4655-7.

Koster, R.D., Suarez, M.J. (1999). A simple framework for examining the interannual variability of land surface moisture fluxes. J. Climate, 12, 19111917.

Kumar, S., Zaitchik, B., Peters-Lidard, C., Rodell, M., Reichle, R., Li, B., Jasinski, M., Mocko, D., (2016). Assimilation of Gridded GRACE Terrestrial Water Storage Estimates in the North American Land Data Assimilation System. J. Hydrometeor., 17, 19511972, http://dx.doi.org/10.1175/JHM-D-15-0157.1.

Kusche, J., Schmidt R., Petrovic, S., Rietbroek, R., (2009). Decorrelated GRACE time-variable gravity solutions by GFZ and their validation using a hydrological model, Journal of Geodesy, https://doi.org/10.1007/s00190-009-0308-3.

Lahoz, W.A., Geer, A.J., Bekki, S., Bormann, N., Ceccherini, S., Elbern, H., Errera, Q., Eskes, H.J., Fonteyn, D., Jackson, D.R., Khattatov, B., (2007). The Assimilation of Envisat data (ASSET) project, Atmos. Chem. Phys., 7, 1773 - 1796.

LeBlanc, M., Tweed, S., Van Dijk, A., Timbal, B., (2012). A review of historic and future hydrological changes in the Murray Darling Basin. Global Planetary Change (8081): 226246.

Leroux, D.J., Pellarin, T., Vischel, T., Cohard, J.-M., Gascon, T., Gibon, F., Mialon, A., Galle, S., Peugeot, C., Seguis, L., (2016). Assimilation of SMOS soil moisture into a distributed hydrological model and impacts on the water cycle variables over the Oum catchment in Benin, Hydrol. Earth Syst. Sci., 20, 2827-2840, https://doi.org/10.5194/hess-20-2827-2016.

Li, B., Rodell, M., Zaitchik, B., Reichle, R., Koster, R., (2012). Assimilation of GRACE terrestrial water storage into a land surface model: Evaluation and potential value 
for drought monitoring in western and central Europe. J. Hydrol., 446 447, 103115, https://doi.org/10.1016/j.jhydrol.2012.04.035.

Li, B., Rodell, M., (2015). Evaluation of a model-based groundwater drought indicator in the conterminous U.S. Journal of Hydrology, 526: 78-88, https://doi.org/10.1016/j.jhydrol.2014.09.02.

Li, B., Rodell, M., Famiglietti, J.S., (2015). Groundwater variability across temporal and spatial scales in the central and northeastern U.S. Journal of Hydrology, 525: 769-780, https://doi.org/10.1016/j.jhydrol.2015.04.033.

Longuevergne, L., Scanlon, B.R., Wilson, C.R., (2010). GRACE Hydrological estimates for small basins: Evaluating processing approaches on the High Plains Aquifer, USA. Water Resources Research, 46, 11, W11517, http://dx.doi.org/10.1029/2009WR008564.

Lorenz, E., (1956). Empirical orthogonal function and statistical weather prediction. Technical Report Science Report No 1, Statistical Forecasting Project. MIT, Cambridge.

Magrin, G., Gay Garca, C., Cruz Choque, D., Gimnez, J.C., Moreno, A.R., Nagy, G.J.,Nobre, C., Villamizar, A., (2007). Latin America. In: Climate Change 2007: Impacts, Adaptation and Vulnerability. Contribution ofWorking Group II to the Fourth Assessment Report of the Intergovernmental Panel on Climate Change [Parry, M.L., O.F. Canziani, J.P. Palutikof, P.J. van der Linden, and C.E. Hanson (eds.)]. Cambridge University Press, Cambridge, UK and NewYork, NY, USA, pp. 581-615.

Magrin, G.O., Marengo, J.A., Boulanger, J.-P., Buckeridge, M.S., Castellanos, E., Poveda, G., Scarano, F.R., Vicua, S., (2014). Central and South America. In: Climate Change 2014: Impacts, Adaptation, and Vulnerability. Part B: Regional Aspects. Contribution of Working Group II to the Fifth Assessment Report of the Intergovernmental Panel on Climate Change [Barros, V.R., C.B. Field, D.J. Dokken, M.D. Mastrandrea, K.J. Mach, T.E. Bilir, M. Chatterjee, K.L. Ebi, Y.O. Estrada, R.C. Genova, B. Girma, E.S. Kissel, A.N. Levy, S. MacCracken, P.R. Mastrandrea, and L.L.White (eds.)]. Cambridge University Press, Cambridge, United Kingdom and New York, NY, USA, pp. 1499-1566.

Mayer-Gürr, T., Zehentner, N., Klinger, B., Kvas, A., (2014). ITSG-Grace2014: a new GRACE 
gravity field release computed in Graz. - in: GRACE Science Team Meeting (GSTM), Potsdam am: 29.09.2014.

Marengo, J.A., (2009). Long-term trends and cycles in the hydrometeorology of the Amazon basin since the late 1920s. Hydrol. Processes 23, 32363244.

Morris, B.L., Lawrence, A.R., Chilton, P.J., Adams, B., Calow, R., Klinck, B.A., (2003). Groundwater and its susceptibility to degradation: A global assessment of the problems and options for management. Early Warning and Assessment Report Series, RS, 03-3.

Munoz, O., I. Leyton, N. Nuez, et al. 2002. Vegetables collected in the cultivated Andean area of northern Chile: total and inorganic arsenic contents in raw vegetables. Journal of Agricultural and Food Chemistry 50 (3): 6427.

Niu, G.-Y., Yang, Z.-L., Mitchell, K. E., Chen, F., Ek, M. B., Barlage, M., Xia, Y. (2011). The community Noah land surface model withmultiparameterization options (Noah-MP): 1 . Model description and evaluation with local-scale measurements. Journal of GeophysicalResearch, 116, D12109, https://doi.org/10.1029/2010JD015139.

Njoku, E.G. et al., (2003). Soil moisture retreival from AMSR-e. IEEE Transactions on Geoscience and Remote Sensing. 41:2, 215-229.

Oke, P.R., Brassington, G.B., Griffin, D.A., Schiller, A., (2008). The Bluelink Ocean Data Assimilation System (BODAS). Ocean Modelling, 21, 4670, http://dx.doi.org/10.1016/j.ocemod.2007.11.002.

Ott, E., Hunt, B.R., Szunyogh, I., Zimin, A.V., Kostelich, E.J., Corazza, M., Kalnay, E., Patil, D.J., Yorke, J.A., (2004). A local ensemble Kalman Filter for atmospheric data assimilation. Tellus, 56A: 415-428.

Pereira, A., Miranda, S., Pacino, M.C., Forsberg, R., (2011). Water Storage Changes from GRACE Data in the La Plata Basin, Geodesy for Planet Earth, International Association of Geodesy Symposia 136,, pp 613-618, http://dx.doi.org/10.1007/978-3-642-20338-1_75.

Pereira, M.P.S., Justino, F., Malhado, A.C.M., Barbosa, H., Marengo, J., (2014). The influence of oceanic basins on drought and ecosystem dynamics in Northeast Brazil. Environ. Res. Lett. 2014, 9, 124013. 
Perez-Carrera, A., Cirelli, A.F., (2009). Arsenic and Water Quality Challenges in South America, Water and Sustainability in Arid Regions, pp 275-293, http://dx.doi.org/10.1007/97890-481-2776-4_17.

Ramirez, B.H., van der Ploeg, M., Teuling, A.J., Ganzeveld, L., Leemans, R., (2017). Tropical Montane Cloud Forests in the Orinoco river basin: The role of soil organic layers in water storage and release, Geoderma, Volume 298, 2017, Pages 14-26, ISSN 0016-7061, http://dx.doi.org/10.1016/j.geoderma.2017.03.007.

Reager, J.T., Thomas, A.C., Sproles, E.A., Rodell, M., Beaudoing, H.K., Li, B., Famiglietti, J.S., (2015). Assimilation of GRACE Terrestrial Water Storage Observations into a Land Surface Model for the Assessment of Regional Flood Potential. Remote Sens. 2015, 7, 1466314679.

Reichle, R.H., McLaughlin, D.B., Entekhabi, D., (2002). Hydrologic Data Assimilation with the Ensemble Kalman Filter. Mon. Wea. Rev. 130, 103114, http://dx.doi.org/10.1175/15200493(2002)130;0103:HDAWTE;2.0.CO;2.

Renzullo, L.J., Van Dijk, A.I.J.M., Perraud, J.M., Collins, D., Henderson, B., Jin, H., Smith, A.B., McJannet, D.L., (2014). Continental satellite soil moisture data assimilation improves root-zone moisture analysis for water resources assessment. J. Hydrol., 519, 27472762. http://dx.doi.org/10.1016/j.jhydrol.2014.08.008.

Rodell, M., Houser, P., Jambor, U., Gottschalck, J., Mitchell, K., Meng, C., Arsenault, K., Cosgrove, B., Radakovich, J., Bosilovich, M., Entin, J., Walker, J., Lohmann, D., Toll, D., (2004). The Global Land Data Assimilation System. Bull. Amer. Meteor. Soc., 85, 381394, http://dx.doi.org/10.1175/BAMS-85-3-381.

Sanso, B., Guenni, L., (1999). Venezuelan rainfall data analysed by using a Bayesian space-time model. Applied Statistics 15, 594-612.

Schellekens, J., Dutra, E., Martnez-de la Torre, A., Balsamo, G., van Dijk, A., Sperna Weiland, F., Minvielle, M., Calvet, J.-C., Decharme, B., Eisner, S., Fink, G., Flrke, M., Peenteiner, S., van Beek, R., Polcher, J., Beck, H., Orth, R., Calton, B., Burke, S., Dorigo, W., and Weedon, G. P., (2017). A global water resources ensemble of hydrological models: the eartH2Observe Tier-1 dataset, Earth Syst. Sci. Data, 9, 389-413, https://doi.org/10.5194/essd-9-389-2017. 
Schunk, R.W., Scherliess, L., Sojka, J.J., Thompson, D.C., (2004). USU global ionospheric data assimilation models, Atmospheric and Environmental Remote Sensing Data Processing and Utilization: an End-to-End System Perspective, (ed. H.-L. A. Huang and H. J. Bloom), Proc. of SPIE, 5548, http://dx.doi.org/10.1117/12.562448, 327-336.

Schumacher, M., Kusche, J., Dll, P., (2016). A systematic impact assessment of GRACE error correlation on data assimilation in hydrological models, Journal of Geodesy, http://dx.doi.org/10.1007/s00190-016-0892-y.

Su, C.-H., Ryu, D., Young, R.I., Western, A.W., Wagner, W., (2013). Inter-comparison of microwave satellite soil moisture retrievals over the Murrumbidgee Basin, southeast Australia. Remote Sensing of Environment, 134, 111.

Sun, T., Ferreira, V., He, X., Andam-Akorful, S., (2016). Water Availability of So Francisco River Basin Based on a Space-Borne Geodetic Sensor. Water 8, 213, http://dx.doi.org/10.3390/w8050213

Swenson, S., Wahr, J., (2002). Methods for inferring regional surface-mass anomalies from Gravity Recovery and Climate Experiment (GRACE) measurements of time-variable gravity. Journal of Geophysical research, 107, B9, 2193. http://dx.doi.org/10.1029/2001JB000576.

Swenson, S., Chambers, D., Wahr, J., (2008). Estimating geocentervariations from a combination of GRACE and ocean model output. Journal of Geophysical research, 113, B08410, http://dx.doi.org/10.1029/2007JB005338.

Syed, T.H., Famiglietti, J.S., Chen, J., Rodell, M., Seneviratne, S.I., Viterbo, P., Wilson, C.R., (2005), Total basin discharge for the Amazon and Mississippi River basins from GRACE and a land-atmosphere water balance, Geophys. Res. Lett., 32, L24404, http://dx.doi.org/10.1029/2005GL024851.

Tangdamrongsub, N., Steele-Dunne, S.C., Gunter, B.C., Ditmar, P.G., and Weerts, A.H., (2015). Data assimilation of GRACE terrestrial water storage estimates into a regional hydrological model of the Rhine River basin, Hydrol. Earth Syst. Sci., 19, 2079-2100, http://dx.doi.org/10.5194/hess-19-2079-2015.

Tedeschi, R.G., Cavalcanti, I.F., Grimm, A.M., (2013). Influences of two types 
of ENSO on South American precipitation. Int. J. Climatol., 33: 1382-1400, http://dx.doi.org/10.1002/joc.3519

Tedeschi, R. G. Collins, M., (2016). The influence of ENSO on South American precipitation during austral summer and autumn in observations and models. Int. J. Climatol., 36: 618635.

Tian, X., Xie, Z., Dai, A., (2008). A land surface soil moisture data assimilation system based on the dual-UKF method and the Community Land Model, J. Geophys. Res., 113, D14127, http://dx.doi.org/10.1029/2007JD009650.

Tian, S., Tregoning, P., Renzullo, L.J., van Dijk, A.I.J.M., Walker, J.P., Pauwels, V.R.N., Allgeyer, S., (2017). Improved water balance component estimates through joint assimilation of GRACE water storage and SMOS soil moisture retrievals, Water Resour. Res., 53, http://dx.doi.org/10.1002/2016WR019641.

Tippett, M.K., Anderson, J.L., Bishop, C.H., Hamill, T.M., Whitaker, J.S., (2003). Ensemble square root filters, Mon. Weath. Rev., 131, 148590.

Tourre, Y.M., Jarlan, L., Lacaux, J.P., Rotela, C.H., Lafaye, M., (2008). Spatio-temporal variability of NDVI-precipitation over southernmost South America: possible linkages between climate signals and epidemics. Environ Res Lett. 2008;3:044008.

Treidel, H., Martin-Bordes, J.L., Gurdak, J.J., (2011). Climate Change Effects on Groundwater Resources: A Global Synthesis of Findings and Recommendations, CRC Press, ISBN 0203120760,9780203120767 .

Tropical Rainfall Measuring Mission (TRMM), (2011). TRMM (TMPA/3B43) Rainfall Estimate L3 1 month 0.25 degree x 0.25 degree V7, Greenbelt, MD, Goddard Earth Sciences Data and Information Services Center (GES DISC), Accessed [Data Access Date] https://disc.gsfc.nasa.gov/datacollection/TRMM_3B43_7.html.

van Dijk, A.I.J.M., (2010). The Australian Water Resources Assessment System: Technical Report 3, Landscape model (version 0.5) Technical Description, CSIRO: Water for a Healthy Country National Research Flagship.

van Dijk, A.I.J.M., Renzullo, L.J., Rodell, M., (2011). Use of Gravity Recovery and Climate Experiment terrestrial water storage retrievals to evaluate model estimates by 
the Australian water resources assessment system, Water Resour. Res., 47, W11524, http://dx.doi.org/10.1029/2011WR010714.

van Dijk, A.I.J.M., Pea-Arancibia, J.L., Wood, E.F., Sheffield, J., Beck, H.E., (2013). Global analysis of seasonal streamflow predictability using an ensemble prediction system and observations from 6192 small catchments worldwide, Water Resour. Res., 49, 27292746, http://dx.doi.org/10.1002/wrcr.20251.

van Dijk, A.I.J.M., Renzullo, L.J., Wada, Y., Tregoning, P., (2014). A global water cycle reanalysis (20032012) merging satellite gravimetry and altimetry observations with a hydrological multi-model ensemble. Hydrol Earth Syst Sci 18:29552973. http://dx.doi.org/10.5194/hess18-2955-2014.

Villar, P.C., (2016). International cooperation on transboundary aquifers in South America and the Guarani Aquifer case, Revista Brasileira de Poltica Internacional, ISSN 1983-3121, Rev. bras. polt. int. vol.59 no.1 Braslia, http://dx.doi.org/10.1590/0034-7329201600107.

Vrugt, J.A., Diks, C.G., Gupta, H.V., Bouten, W., Verstraten, J.M., (2005). Improved treatment of uncertainty in hydrologic modeling: Combining the strengths of global optimization and data assimilation. Water Resour. Res, 41, W01017, http://dx.doi.org/10.1029/2004WR003059.

Vrugt, J.A., ter Braak, C.J.F., Diks, C.G.H., Schoups, G., (2013). Advancing hydrologic data assimilation using particle Markov chain Monte Carlo simulation: theory, concepts and applications, Advances in Water Resources, Anniversary Issue - 35 Years, 51, 457-478, http://dx.doi.org/10.1016/j.advwatres.2012.04.002.

Wahr, J., Molenaar, M., Bryan, F., (1998). Time variability of the Earth's gravity field' Hydrological and oceanic effects and their possible detection using GRACE. Journal of Geophysical research, 103, B12, 30, 205-30, 229. http://dx.doi.org/10.1029/98JB02844.

Whitaker, J.S., Hamill, T.M., (2002). Ensemble data assimilation without perturbed observations, Mon. Wea. Rev., 130, 19131924.

Wiese, D.N., (2015). GRACE monthly global water mass grids NETCDF RELEASE 5.0. Ver. 5.0. PO.DAAC, CA, USA. http://dx.doi.org/10.5067/TEMSC-OCL05. 
Xavier, L., Becker, M., Cazenave, A., Longuevergne, L., Llovel, W., Filho, O.C.R. (2010). Interannual variability in water storage over 2003-2008 in the Amazon Basin from GRACE space gravimetry, in situ river level and precipitation data. Remote Sens. Environ., 114, 1629-1637, http://dx.doi.org/10.1016/J.RSE.2010.02.005.

Yates, D.N., (1997). Climate change impacts on the hydrologic resources of South America: an annual, continental scale assessment, Climate Research, Vol. 9, No. 1-2, December 29, pp. $147-155$.

Yeh, P.J.F., Swenson, S.C., Famiglietti, J.S., Rodell, M., (2006). Remote sensing of ground water storage changes in Illinois using the Gravity Recovery and Climate Experiment (GRACE). Water Resources Research, 42, W12203. http://dx.doi.org/10.1029/2006WR005374.

Yu, Y., Disse, M., Yu, R., Yu, G., Sun, L., Huttner, P., Rumbaur, C., (2015). Large-Scale Hydrological Modeling and Decision-Making for Agricultural Water Consumption and Allocation in the Main Stem Tarim River, China. Water, 7, 2821-2839.

Yue, S., Wang, C., (2004). The Mann-Kendall Test Modified by Effective Sample Size to Detect Trend in Serially Correlated Hydrological Series, Water Resources Management 18: 201, https://doi.org/10.1023/B:WARM.0000043140.61082.60.

Zaitchik, B.F., Rodell, M., Reichle, R.H., (2008). Assimilation of GRACE terrestrial water storage data into a land surface model: results for the Mississippi River Basin. J Hydrometeorol 9(3):535548, http://dx.doi.org/10.1175/2007JHM951.1. 